TI 2013-094/ VIII

Tinbergen Institute Discussion Paper
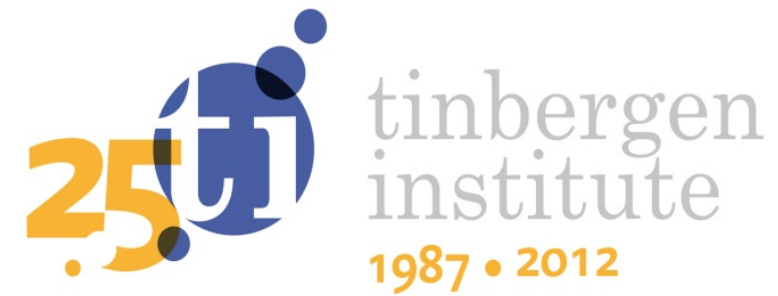

\title{
Resource Extraction in a Political Economy Framework
}

Karolina Ryszka

Faculty of Economics and Business Administration, VU University Amsterdam, and Tinbergen Institute. 
Tinbergen Institute is the graduate school and research institute in economics of Erasmus University Rotterdam, the University of Amsterdam and VU University Amsterdam.

More TI discussion papers can be downloaded at http://www.tinbergen.nl

Tinbergen Institute has two locations:

Tinbergen Institute Amsterdam

Gustav Mahlerplein 117

1082 MS Amsterdam

The Netherlands

Tel.: +31(0)205251600

Tinbergen Institute Rotterdam

Burg. Oudlaan 50

3062 PA Rotterdam

The Netherlands

Tel.: +31(0)10 4088900

Fax: $+31(0) 104089031$

Duisenberg school of finance is a collaboration of the Dutch financial sector and universities, with the ambition to support innovative research and offer top quality academic education in core areas of finance.

DSF research papers can be downloaded at: http://www.dsf.nl/

Duisenberg school of finance

Gustav Mahlerplein 117

1082 MS Amsterdam

The Netherlands

Tel.: +31(0)20 5258579 


\title{
Resource Extraction in a Political Economy Framework
}

\author{
Karolina Ryszka*
}

July 15, 2013

\begin{abstract}
We analyze resource extraction in a political economy setting by introducing a political leader who optimizes both his own and the society's welfare function. We find that accounting for the private utility of a political elite, its higher discount rate and a different time horizon generally speeds up extraction. The higher than optimal resource extraction is not only relevant in welfare terms, but also regarding possible consequences with respect to climate change. The effect of higher extraction caused by a political leader directly accroaching resources does not hold in a decentralized private ownership economy where the government strives to raise revenues through taxation. We endogenize the political economy framework and show that the politician's discount factor is higher than the social discount factor due to the probability of losing power. The weight that the political leader attaches to social welfare is determined by the way the probability of staying in power depends on the welfare of the society.
\end{abstract}

Keywords: exhaustible resources, oil, dictatorship, political economy, taxation, climate change

JEL Classification: Q31, Q38, Q54

${ }^{*}$ Department of Economics, VU University Amsterdam; Tinbergen Institute 


\section{Introduction}

In this paper, we investigate non-renewable resource depletion in a political economy framework. In particular, we consider an economy where the political elite disposes of discretionary decision making power regarding the state owned resources.

We analyze theoretically and quantitatively whether and how optimal depletion changes if one deviates from the Social Planner optimality framework by including political economy features. We introduce a political leader who optimizes a weighted sum of his own and the society's welfare into a model of resource depletion. The political leader's discount rate differs from the discount rate of the society. Also, his time horizon is finite, whereas the social optimization problem extends to infinity. These features generally imply higher extraction. As compared to this model with a political leader deciding on resource extraction and directly accroaching a part of the resource, resource extraction in our numerical examples is found to be lower in a decentralized private ownership economy where the government strives to raise revenues via taxation.

In a discrete finite time setting, we motivate the choice of the form of the political leader's optimization problem. The political elite's higher discount rate results from the probability of losing power. This 'staying in power' or 're-election' probability is determined by social welfare and, depending on the functional form, induces the politician to also account for the utility of the society.

The theoretical framework at hand can be related to the literature on the resource curse where political leadership, or generally, the quality of institutions are used as one explanatory factor for the bad economic performance and low economic growth in resource rich countries. ${ }^{1}$ Whereas some studies seem to confirm the role of resource rich countries' political economy on their economic performance (Sachs and Warner, 1995, 2001; Gylfason, 2001), the theoretical literature still offers a variety of possible mechanisms. Tornell and Lane (1999), for instance, find a "voracity effect" when powerful groups interact via a fiscal process which results in a disproportionately high increase in fiscal redistribution. Mehlum, Moene, and Torvik (2006) note that the quality of institutions determines the scope of rent seeking. Deacon (2003) shows theoretically and empirically that public good provision varies systematically with the quality and form of government. He concludes that public good provision is larger in more inclusive regimes such as democracies than in autocracies. Bulte and Damania (2008) model the government explicitly as an active player with own objectives and constraints whose behavior, additional to the rent seeking of private agents, gives a possible explanation for the resource curse. Similarly, Leite and

\footnotetext{
${ }^{1}$ Frankel (2010) and van der Ploeg (2010) survey a variety of hypotheses and papers on the resource curse.
} 
Weidmann (1999) highlight the role of corruption in the presence of resource abundance and its effects on growth in a general equilibrium framework.

In contrast to these more decentralized mechanisms, Robinson, Torvik, and Verdier (2006) develop a simple two period probabilistic voting model and try to assess the political incentives that are generated by resource endowments. They find that politicians tend to over-extract natural resources. In their model, the overall impact of resource booms on the economy depends on institutions as they determine to which extent political incentives are mapped into policy outcomes. Another attempt to place models of resource depletion in a political economy framework is made by van der Ploeg (2011), for instance, who derives political counterparts of the Hotelling and the Hartwick rules in a fractionalized economy. There, each societal fraction owns a part of the national resource stock; yet, ownership rights on the stock are not secure as the resource fields are interconnected and seepage occurs. This induces a dynamic common-pool problem which results in prices and resource depletion increasing faster than suggested by the Hotelling rule. In another paper, Van der Ploeg (2012) analyzes how a possible regime switch affects the resource depletion of a monopolistic private owner. He assumes that two types of government are possible: a benevolent and a grabbing populist government. The higher initial oil depletion rates are driven by the higher risk of confiscation in case a regime switch occurs. A higher regime switching probability induces higher resource depletion in both regimes.

The quest for political economy determinants of resource depletion decisions is important for several reasons. Empirical evidence suggests that governments and politicians do not always act as welfare maximizers. This does not only concern resource depletion. Also the saving and investment behavior of resource rich economies might be considered 'non-optimal' in terms of maximizing a (generationally equitable) utility function. ${ }^{2}$ Van der Ploeg (2011) observes the need to "introduce political economy features" in order to explain economic outcomes that do not comply with the efficiency of the Hotelling and Hartwick rules. Though various amendments and extensions were made to Hotelling's (1931) basic analysis in order to account for different complexities and extensions: ${ }^{3}$ important factors accounting for real world resource depletion decisions might not be captured by the generally employed stylized models of resource depletion.

Also, analyzing resource extraction in a political economy framework might reveal

\footnotetext{
${ }^{2}$ With genuine saving rates seen as an indicator for the sustainable development of a country (Pearce, Hamilton, and Atkinson, 1996), Hamilton and Clemens (1999) find suboptimally low genuine saving rates in resource-rich countries, which seem to have serious welfare consequences (Hamilton, Ruta, and Tajibaeva, 2005).

${ }^{3}$ Hotelling and other researchers refined and amended the famous 'Hotelling rule' by investigating issues related to the effects of resource price and output paths in case of monopolies, in the presence of (production dependent) extraction costs and taxes, as well as in the need of fixed investments. The analysis was extended to general equilibrium frameworks.
} 
what actually is the attainable second best for resource-rich countries with a state-owned resource stock and politically controlled resource extraction. Dasgupta (2001) remarks that "intertemporal welfare economics was developed for a society in which the State is not only trustworthy, it also optimizes on behalf of its citizens. Policy prescriptions emerging from the theory are for Utopia, [...]". It does not seem unreasonable that decisions on natural resource depletion taken by politicians (in case the resources are state-owned or the resource management is state-controlled) are not only based on social welfare concerns and that the information available to the decision maker is much more limited than it is generally supposed in the rational agents' framework. Knowledge of the mechanisms and their consequences might help in developing welfare-enhancing policies for resource-rich countries.

Another aspect is related to the relevance of resource depletion and usage for the environment. Abstracting from the fact that exhaustible resources will not exist any more after extraction and thus the environment per se is changed, the consumption of resources, especially oil and gas, has consequences for climate change. A higher speed of resource depletion on global level might worsen the impact of resource usage on the climate (Ramanathan, 1980). Also Withagen (2012) acknowledges the role of the resource market structure (such as the cartel-versus-fringe model in his case) for the climate due to the strong relationship between climate change and $\mathrm{CO} 2$ emissions as a consequence of burning fossil fuel. The same reasoning can be applied to the political economy features influencing the rate of resource extraction in our model.

The paper at hand is an attempt to build a political economy framework for models of resource depletion. Efforts to analyze the resource extraction in an intertemporal setting accounting for the utility of the government or the political elite of a resource rich country have not been made yet, to my knowledge.

In Sections 2.1 to 2.3, the political economy framework is gradually developed. Section 2.4 compares the resource extraction paths in a political economy framework with the outcome in a decentralized economy where politicians try to raise revenue by taxing different sectors of the economy. In Section 3 we endogenize the weight the political leader attaches to societal welfare by modelling the impact of resource extraction and resource use on the political leader's hazard of staying in power in a discrete time setting. Furthermore, we provide a motivation for the political leader's higher discount rate. Section 4 concludes. 


\section{Political Economy Framework}

\subsection{The Political Leader's Utility Function}

We depart from the notion of a benevolent Social Planner and model the decision on natural resource depletion as a consequence of the optimization problem of a political leader in a resource rich country. The political leader's utility function is assumed to be a linear combination of the utility of his private consumption, defined more broadly as private benefits, and the social welfare function. ${ }^{4}$ Thus, let the political leader's one-period utility function be denoted as:

$$
u\left(C_{t}^{P}, C_{t}^{S}\right)=(1-\gamma) u_{P}\left(C_{t}^{P}\right)+\gamma u_{S}\left(C_{t}^{S}\right)
$$

with $u_{P}\left(C_{t}^{P}\right)$ being the political leader's utility from private consumption, $C_{t}^{P}$, defined more broadly as private benefits, and $u_{S}\left(C_{t}^{S}\right)$ denoting the social welfare function in period $t$, depending on the level of societal consumption $C_{t}^{S}$. The parameter $\gamma \in[0,1]$ determines to which extent the politician accounts for the social welfare, with $\gamma=1$ being the usual Social Planner's problem. In the case the political leader is an absolute dictator who entirely disregards any social welfare considerations, i.e. if $\gamma=0$, the optimization problem reduces to maximizing solely the politician's private utility. The extreme cases are neither interesting nor insightful, thus, in what follows, we will focus on $\gamma \in(0,1)$.

This formulation of a political leader's utility function relies on the following assumptions: Firstly, the political elite is the direct recipient of the resources extracted. This is a sensible assumption for many countries where resource extraction is conducted by stateowned companies. To a certain degree, this can also be the case in countries where the government grants licences to private firms as this might be a means to indirectly control the extracted amount (Crommelin and Thompson, 1977).

Furthermore, the political leader or the political elite is not uncontested. The politician cannot solely maximize his own utility while being entirely myopic regarding the welfare of the country's population. According to the type of regime which ranges from democracy to autocracy the reasons for the incumbent being challenged are likely to differ. ${ }^{5}$ In a

\footnotetext{
${ }^{4}$ The objective function will be similar to the one employed by Robinson and Torvik (2005). They model the politician $i$ 's per period utility as $U_{t}^{i}=X_{t}^{i}+\frac{1}{2} \alpha Y_{t}^{i}$, with $i=A, B$ denoting two regional parties and two groups of voters of equal size $\frac{1}{2}$. Politicians and voters with the same label belong to the same region. In their probabilistic voting model each politician cares about his own utility and about the political outcome for agents in his region. $X_{t}^{i}$ is the income of the politician in period $t, Y_{t}^{i}$ is the income of each member in group $i$ and the parameter $\alpha$ governs how the politician values the outcome for his own group.

${ }^{5}$ Labelling a country's regime as an autocracy or a democracy is not an easy task and there exists a branch of political science literature concerned with this issue. For simplicity one could follow Deacon (2003) in distinguishing between autocracies, democracies and mixed regimes.
} 
democratic regime the incumbent is challenged by political opponents during recurrent elections. As the political leader is the direct recipient of the resource revenues, it is highly profitable to stay in power. Consequently, the incumbent will have an incentive to care about the well-being of the country's population in order to avoid his deselection in case the electorate was dissatisfied with his governance.

Also in case of an autocratic regime, it is unlikely that political elites are never uncontested. The presence of resource rents provides incentives for potential political challengers to seek power, for instance by conducting a coup d'état. ${ }^{6}$

The relative weighting of private benefits to social welfare is determined by the regime. In a democracy $\gamma$ is likely to be higher than in an autocracy as the threat of being voted out of office if the government fails to satisfy the electorate is immediate. In the case of an autocracy, the political leader is prone to pay less attention to social welfare. Instead, he might use private benefits for activities that are not beneficial for the country's population, but that eventually preserve his power, such as repression of the opposition or the construction of white elephants, i.e. investment projects with negative social surplus (Robinson and Torvik, 2005). Note that we abstract from models of political competition such as opportunistic models giving rise to political business cycles (Besley, 1977; Drazen and Eslava, 2006; Grossman and Helpman, 1996), and from dynamics within the government (Persson, Roland, and Tabellini, 2007). ${ }^{7}$ Furthermore, we do not consider modelling different societal groups. Hence, political leaders do not pursue any partisan politics as in Alesina and Tabellini (1987) and Tabellini and Alesina (1990), but limit themselves to eventually maximizing aggregate social welfare.

Regarding the intertemporal variant of the utility function in (1), the issues to be considered are the political leader's and society's discount factors and their respective time horizons. The social rate of time preference, i.e. a discount rate for the society as a whole, is $\rho>0$. Even in case it is higher than the pure rate of time preference, i.e. accounting for the tiny possibility that live on earth will cease to exist (Dasgupta and Heal, 1979), it is lower than the political leader's discount rate $\delta$ which denotes the politician's rate of time preference. One reason for his intertemporal preferences to be particularly present-biased is that the political leader will be in power in the future only with a certain probability. Furthermore, he himself lacks any direct concern for future

\footnotetext{
${ }^{6}$ As an example, Casellli (2006) notes that oil wealthy Nigeria has had eight successful coups since its independence in 1960 .

${ }^{7}$ Opportunistic models of political competition assume that fiscal policy plays a key role in pre-electoral manipulation of the electorate. In these models, the government is assumed to be purely opportunistic and only concerned about staying in power, and therefore it pursues inefficient policies and overborrowing, giving rise to Political Business Cycles in the economy. Recent studies take differences between developed and developing countries, the degree of democracy and transparency into account. According to empirical findings, PBCs are more pronounced in countries where politicians can be removed from office without high costs, where the degree of transparency and democracy are at intermediate levels (Brender and Drazen, 2005). Thus, PBCs are more likely to occur in developing countries and new democracies.
} 
generations (in contrast to the society which does care for its descendants). Thus, $\rho<\delta$ sensibly holds.

Also, the planning horizon differs between the political leader on the one hand, and the society on the other hand. While the optimal time horizon for the society might be infinite or finite, the political leader's time horizon is shorter than the society's. Hence, we assume that politicians are short-lived, as in Grossman and Helpman (1998). The reason might be that the maximum number of their terms of office is constrained in a democratic regime. But even in a more autocratic regime, the political leader faces a different time horizon as he will not live infinitely long and thus will not be able to enjoy his direct private benefits infinitely. Yet, in contrast to Grossman and Helpman (1998), we suppose that the government does not solely care about the well-being of the generation alive, but also about the society's (discounted) welfare extending to infinity, as the current generations also demonstrate perfect altruism and concern for the well-being of their descendants (Ramsey, 1928).

The model presented in this section is a closed economy model without population growth, and entails a productive sector. Exhaustible resources are used together with capital and labour to produce the only (both consumption and investment) good of the economy according to a Cobb-Douglas production function. In order to focus on the political economy framework, we leave open economy considerations aside.

The stock of the exhaustible natural resource is owned by the government who decides on the resource depletion, $R_{t}$, at every instant in time. The natural resource can either be used for productive activities or appropriated by the political leader, thus $R_{t}=R_{t}^{P}+R_{t}^{S}$, where $R_{t}^{S}$ denotes the resource stock that is employed by the productive sector of the society, whereas $R_{t}^{P}$ is used by the political elite for private consumption. Furthermore, we assume that $R_{t}^{P}=C_{t}^{P}$, i.e. the resource yields direct benefits or 'consumption' to the political leader. This is clearly a simplification. The interpretation is that the natural resources can be appropriated by the political leader in such a way that they do not yield any benefit to the population and do not serve as input into productive activity. ${ }^{8}$ Furthermore, the resource depletion equation reads:

$$
\dot{S}_{t}=-R_{t}, \quad S(0)=S_{0}
$$

with $S_{t}$ being the stock of the natural resource still in situ, and $S_{0}$ denoting the initial natural resource stock. We write $\dot{x}(t)=d x(t) / d t$ for any variable $x(t)$. In order to shorten

\footnotetext{
${ }^{8} \mathrm{We}$ are referring to the discussion above in this Section 2.1 ; the political leader or the political elite might thus use the resource revenues to buy off his opponents, construct white elephants or suppress the opposition. Another interpretation would be that the political elite sells the resource at world market prices abroad and buys goods abroad; one could think of arms or luxury goods for instance. This amount of resources is not used for domestic productive activity and the resource revenues are not used to buy any consumption goods produced in the market.
} 
the notation we use $X_{t}$ for $X(t)$, i.e. in case variable $X$ is a function of $t$ in continuous time. The time path of the depletion of exhaustible resources must satisfy:

$$
\int_{0}^{\infty} R_{t} d t \leq S_{0}
$$

Physical or human capital $K_{t}$, natural resources $R_{t}^{S}$ and labour $L_{t}$ are used to produce output $Y_{t}$. The production function $Y_{t}=F\left(K_{t}, L_{t}, R_{t}^{S}\right)$ satisfies the Inada conditions and is characterized by constant returns to scale. As in van der Ploeg (2011), we assume that natural resources are necessary for production, but not essential. This means that though output from production is zero if no resources are used in the production (i.e. the resource is a necessary input in order to obtain nonzero output), there exists a feasible program along which consumption is bounded away from zero. Natural resources are thus substitutable by capital. If the resource was essential, consumption would inevitably converge to zero if the resource stock was also converging to zero. Moreover, the production function is of the following Cobb-Douglas form:

$$
Y=K^{\alpha} R^{S^{\beta}} L^{1-\alpha-\beta}, \quad \text { with } \quad \alpha>\beta>0, \alpha+\beta<1
$$

In the following we assume that labour supply is completely inelastic, individuals do not value leisure and labour supply is therefore not a decision variable; we thus normalize the input factor labour to one. For the sake of exposition we will retain the variable $L$ in our notation. Capital evolves according to

$$
\dot{K}=Y-C^{S}
$$

Assuming utilitarian preferences, it is reasonable to consider different discount rates for the political elite and the population. ${ }^{9}$ We denote the political leader's discount rate as $\delta$ and assume that $\delta>\rho$. The political leader maximizes the following intertemporal utility function:

$$
U=(1-\gamma) \int_{0}^{\infty} u_{P}\left(C_{s}^{P}\right) e^{-\delta s} d s+\gamma \int_{0}^{\infty} u_{S}\left(C_{s}^{S}\right) e^{-\rho s} d s
$$

where $\rho$ denotes the pure rate of time preference, $u_{P}\left(C^{P}\right)$ is the political leader's direct utility from the private benefits he can gain using the resources, and $u_{S}\left(C^{S}\right)$ is the instantaneous utility of the population. Thus, $\int_{0}^{\infty} u_{S}\left(C_{s}^{S}\right) e^{-\rho s} d s$ can be viewed as the social welfare function.

The instantaneous utility functions for the society and the politician are of the following

\footnotetext{
${ }^{9}$ In section 3 we provide a motivation for $\delta>\rho$.
} 
standard form:

$$
\begin{aligned}
& u_{S}\left(C^{S}\right)=\frac{\left(C^{S}\right)^{1-1 / \theta}-1}{1-1 / \theta}, \quad \text { if } \theta \neq 1, \quad u_{S}\left(C^{S}\right)=\ln \left(C^{S}\right) \text { if } \theta=1, \quad \text { and } \\
& u_{P}\left(C^{P}\right)=\frac{\left(C^{P}\right)^{1-1 / \psi}-1}{1-1 / \psi}, \quad \text { if } \psi \neq 1, \quad u_{P}\left(C^{P}\right)=\ln \left(C^{P}\right) \text { if } \psi=1,
\end{aligned}
$$

where $\theta \equiv-\frac{u^{\prime}\left(C^{S}\right)}{C^{S} u^{\prime \prime}\left(C^{S}\right)}$, is the elasticity of intertemporal substitution of the society, and $\psi \equiv$ $-\frac{u^{\prime}\left(C^{P}\right)}{C^{P} u^{\prime \prime}\left(C^{P}\right)}$ denotes the same for the politician. Its inverse corresponds to the coefficient of relative risk aversion and of relative intertemporal inequality aversion (van der Ploeg, 2011).

The present value Hamiltonian for this problem is:

$$
H \equiv(1-\gamma) e^{-\delta t} u_{t}^{P}\left(C_{t}^{P}\right)+\gamma e^{-\rho t} u_{t}^{S}\left(C_{t}^{S}\right)+\lambda(t)\left(K_{t}^{\alpha} R_{t}^{S^{\beta}} L_{t}^{1-\alpha-\beta}-C_{t}^{S}\right)-\mu(t)\left(R_{t}^{S}+R_{t}^{P}\right)
$$

with $\lambda$ and $\mu$ being the marginal utility for an extra unit of capital and natural resources. The details of how to solve the present value Hamiltonian in (7) are displayed in the Appendix A.1. Using that the marginal product of the natural resource equals its social shadow price, $q_{t}$, the marginal product of capital equals the interest rate, and the first order conditions, we write the Hotelling rule: ${ }^{10}$

$$
\frac{\dot{q}_{t}}{q_{t}}=r_{t}
$$

This equation has the standard interpretation of the Hotelling rule: the rate of capital gains (i.e. the appreciation in value of the unextracted resource stock) must equal the rate of return earned in holding any other asset. Notice that $r_{t}=\rho-\frac{u_{S}^{\prime \prime}\left(C_{t}^{S}\right) \dot{C}_{t}^{S}}{u_{S}^{\prime}\left(C_{t}^{S}\right)}$ holds along the socially optimal path. Using the elasticity of intertemporal substitution, we can write this as $\frac{\dot{C}_{t}^{S}}{C_{t}^{S}}=\left(r_{t}-\rho\right) \theta$. This expression is equal to the case of a pure Social Planner model. The political leader's consumption path, in contrast, is denoted by $C_{t}^{P}=C_{0}^{P} e^{-\delta \psi t}$. The political elite's consumption is thus monotonically decreasing as $\frac{\dot{C}_{t}^{P}}{C_{t}^{P}}=-\delta \psi<0 .{ }^{11}$

The introduction of the political leader effectively decreases the amount of resources available for the society. Given $S_{0}, K_{0}$ and $\gamma$, the politician 'consumes' a part of the original resource stock, $S_{0}^{P}=\int_{s=0}^{\infty} R_{s}^{P} d s$ with $R_{t}^{P}=C_{t}^{P}$. The remaining resources $S_{0}^{S}=S_{0}-S_{0}^{P}$

\footnotetext{
${ }^{10}$ Note that one should not mistake the shadow price in this model with a market price of a unit of resource. In this model specification, there are no spot prices of a resource unit as a decentralized market for resources is absent. The 'prices' we are referring to are shadow prices in a Social Planner's economy. A decentralized markets economy with market prices will be introduced in section 2.4 .

${ }^{11}$ This formulation relies on the assumption that the politician does not invest in his country's capital stock. This seems naural, as the only asset the dictator has at hand is the non-renewable resource. Also, another interpretation is that the politician is not interested in investing in the economy's capital stock as he does not gain from a better performance of the economy and does not consume the economy's final output $Y$.
} 
are used for social production and are extracted according to the Hotelling rule as in (8) with $\frac{\dot{q}_{t}}{q_{t}}=r_{t}$. The resource depletion of $S_{0}^{P}$ is governed by $\frac{\dot{R}_{t}^{P}}{R_{t}^{P}}=-\delta \psi$ and is responsible for the higher initial overall resource extraction. The less the political elite cares about societal well-being, i.e. the lower $\gamma$ and the higher $S_{0}^{P}$ relatively to $S_{0}^{S}$, the more severe is the effect on the initial extraction periods.

This gives us a first proposition:

Proposition 1. The social consumption and extraction levels in the presence of the political leader differ from the pure Social Planner case. The political leader's higher impatience generally gives rise to higher resource extraction levels and to a societally suboptimal resource extraction path as compared to the Social Planner solution.

Proof. See Appendix A.1.

The focus of the paper is the political economy mechanism; we thus do not strive to obtain a closed form solution to the model presented above. ${ }^{12}$ Yet, we hope to characterize some features of the paths of $\left\{C_{t}^{S}, C_{t}^{P}, K_{t}, R_{t}^{S}, S_{t}\right\}_{t=0}^{\infty}$ which describe the solution to the model. Our numerical method is briefly decribed in the Appendix A.3.1 and the parametrization used is displayed in Appendix A.3.2. Our numerical examples in Figure 1 show that both the societal consumption and the consumption of the political elite converge to zero in the long run. Also, the amount of resources extracted converges to zero. As theory predicts, capital converges to zero only in the long run, an initial increase in the capital stock is possible. Also, societal consumption and extraction in the presence of the political leader are lower as in the pure Social Planner case. Moreover, aggregate resource extraction is accelerated in the presence of the political elite, and social welfare is lower as compared to the Social Planner case.

Quantitatively though not qualitatively, these results are driven by the parameter values. Using a smaller societal weight $(\gamma=0.3$ instead of 0.9$)$ results in lower social consumption and resource usage, whereas the aggreate resource usage is even more pronounced in the first periods as can be seen in the two bottom two graphs of Figure $1{ }^{13}$

\subsection{Resource Extraction Model with Different Time Horizons}

The next amendment we consider are differing time horizons. Let us assume that the planning horizon of the society remains infinite, while the political leader's planning horizon

\footnotetext{
${ }^{12}$ Benchekroun and Withagen (2011) give a complete analytical solution to the Dasgupta-Heal-SolowStiglitz model for the case in which the production elasticity of man made capital is $0<\alpha<1$ and the production elasticity of the exhaustible resource is $(1-\alpha)$. Our model, however, is more complicated.

${ }^{13}$ As can be seen in Appendix A.1, there might exist parameter values for which the initial aggregate resource extraction is not higher than in the Social Planner case. This might be in particular true in case of a high $\gamma$ and a very low $S_{0}^{P}$. Yet, so far we were unable to find parameter values which can sustain the equilibrium paths.
} 

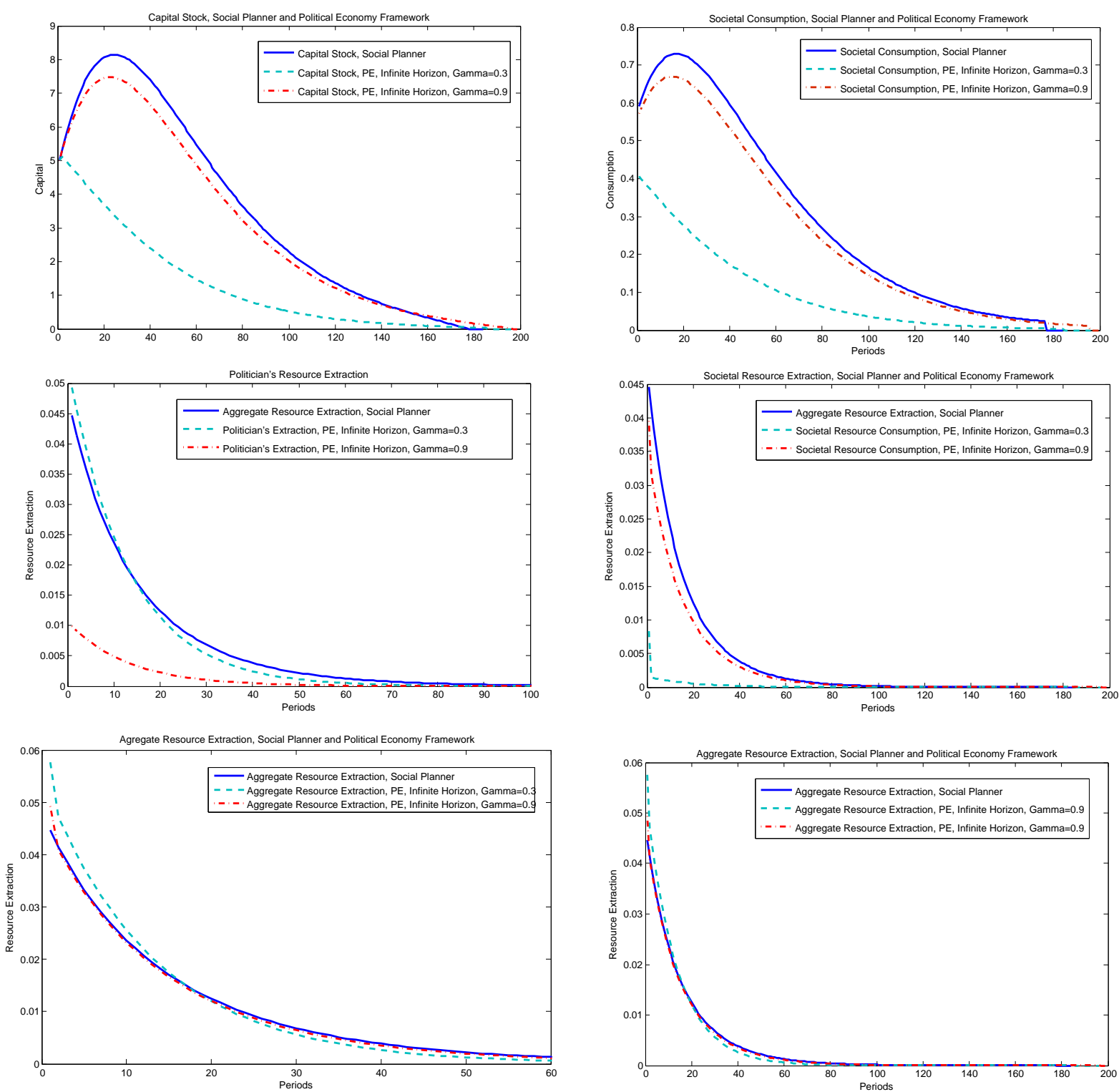

Figure 1: Consumption, Investment and Resource Extraction Paths in a Social Planner Economy and in the Political Economy Framework with Infinite Horizon $(\gamma=0.3,0.9)$

ends at a fixed $T$. Everything else in the model remains unchanged.

The objective function to be maximized by the politician thus reads:

$$
\begin{aligned}
U & =(1-\gamma) \int_{0}^{T} u_{P}\left(C_{s}^{P}\right) e^{-\delta s} d s+\gamma \int_{0}^{\infty} u_{S}\left(C_{s}^{S}\right) e^{-\rho t} d s \\
& =(1-\gamma) \int_{0}^{\infty} u_{P}\left(C_{s}^{P}\right) e^{-\delta s} I(s) d s+\gamma \int_{0}^{\infty} u_{S}\left(C_{s}^{S}\right) e^{-\rho s} d s
\end{aligned}
$$

with $I(t)$ being an indicator function that takes the value one if $t \leq T$ and zero if $t>T$. 
The present value Hamiltonian for this problem looks as follows:

$H \equiv(1-\gamma) e^{-\delta t} u_{P}\left(C_{t}^{P}\right) I(t)+\gamma e^{-\rho t} u_{S}\left(C_{t}^{S}\right)+\lambda(t)\left[K_{t}^{\alpha}\left(R_{t}^{S}\right)^{\beta} L_{t}^{1-\alpha-\beta}-C_{t}^{S}\right]-\mu(t)\left[R_{t}^{P}+R_{t}^{P}\right]$

Notice that the objective function is nonsmooth. To make the problem more tractable we split it into two distinct maximization problems and then find a solution for the joint maximization problem. First, the political leader maximizes his intertemporal welfare function:

$$
W^{P}=\max \int_{s=0}^{T} u_{P}\left(C_{s}^{P}\right) e^{-\delta s} d s,
$$

where $C_{t}^{P}=R_{t}^{P}$, and subject to the following constraints:

$$
\dot{S}_{t}^{P}=-R_{t}^{P}, \quad S_{0}^{P}=S^{P}(0), \quad \text { or } \quad \int_{s=0}^{T} R_{s}^{P} d s=S_{0}^{P}
$$

$S_{0}^{P}$ is a part of $S_{0}$ that is exploited for the politician's benefits only, and is taken as given for now. In the later analysis the optimal $S_{0}^{P}$ needs to be determined. The Hamiltonian looks as follows:

$$
H \equiv e^{-\delta t} u_{P}\left(C_{t}^{P}\right)-\mu R_{t}^{P}
$$

In this case we consider a pure 'consumption economy'; the shadow price of consumption is simultaneously the shadow price of the resource. The first order conditions together with the utility specification in (6) imply that the optimal consumption path and the depletion rate change in the same way:

$$
\frac{\dot{R_{t}^{P}}}{R_{t}^{P}}=-\psi \delta
$$

The depletion path is thus monotonically decreasing and the speed is governed by the discount rate and the elasticity of intertemporal substitution. If both $\psi$ and $\delta$ are high the initial consumption and resource depletion will be relatively high in the first periods. Due to (12) we can compute the initial $C_{0}^{P}$ for a given $S_{0}^{P}$ :

$$
C_{0}^{P}=S_{0}^{P}\left[\int_{s=0}^{T} e^{-\psi \delta s}\right]^{-1} d s=\frac{\psi \delta}{1-e^{-\psi \delta T}} S_{0}^{P} .
$$

Using the instantaneous utility function in (6), the political leader's maximized intertemporal welfare thus equals:

$$
W^{P}=\max \int_{s=0}^{T} u_{P}\left(C_{s}^{P}\right) e^{-\delta s} d s=\int_{s=0}^{T} \frac{\left[\frac{S_{0}^{P} \psi \delta}{1-e^{-\psi \delta T}} e^{-\psi \delta s}\right]^{1-1 / \psi}-1}{1-1 / \psi} d s
$$


This equation solely depends on $S_{0}^{P}$, i.e. the amount of the resource stock, that the political leader ends up accroaching, and on his time horizon $T$.

Next, let us consider the utility maximization problem of the society, i.e. from the pure Social Planner's perspective. The welfare function reads

$$
W^{S}=\max \int_{s=0}^{\infty} u_{S}\left(C_{s}^{S}\right) e^{-\delta s} d s
$$

subject to (2), (3) and (4).

The Hamiltonian looks as follows:

$$
H \equiv e^{-\rho t} u_{S}\left(C_{t}^{S}\right)+\lambda(t)\left[K_{t}^{\alpha}\left(R_{t}^{S}\right)^{\beta} L_{t}^{1-\alpha-\beta}-C_{t}^{S}\right]-\mu(t) R_{t}^{S}
$$

The first order conditions imply the usual Hotelling rule for the movement of the shadow price: $\frac{\dot{q}_{t}}{q_{t}}=r_{t}$. The shadow price equals now the shadow price in the case of a pure Social Planner, yet, with an initial resource endowment of $S_{0}^{S}$.

Having found the optimal investment, depletion and consumption programs for the two problems separately with $S_{0}^{i}, i=S, P$ given, we can maximize the joint welfare function varying $S_{0}^{P}$ and $S_{0}^{S}$ such that their sum equals a given $S_{0}$ :

$$
(1-\gamma) W^{P}\left(S_{0}^{P}\right)+\gamma W^{S}\left(S_{0}^{S}\right) \text { s.t. } S_{0}^{P}+S_{0}^{S}=S_{0}
$$

From the first order condition for (19) it follows that:

$$
\frac{(1-\gamma)}{\gamma}=\frac{\partial W^{S}\left(S_{0}-S_{0}^{P}\right) / \partial S_{0}^{P}}{\partial W^{P}\left(S_{0}^{P}\right) / \partial S_{0}^{P}} .
$$

While we can immediately derive $\frac{\partial W^{P}\left(S_{0}^{P}\right)}{\partial S_{0}^{P}}$ analytically, this is not possible for the social welfare function without solving the entire model analytically.

The numerical examples in Figure 2 illustrate the effect of a politician having a limited time horizon on the extraction rates. The higher initial extraction is driven by the extractive behavior of the political elite during the time it is in place. Equation (15) provides some intuition for this. If $T \rightarrow \infty$, the initial resource consumption of the politician equals $C_{0}^{P}=\psi \delta S_{0}^{P}$. The smaller $T$ becomes, the higher is initial consumption $C_{0}^{P}=\frac{\psi \delta}{1-e^{-\psi \delta T}} S_{0}^{P}>\psi \delta S_{0}^{P} \cdot{ }^{14}$

\footnotetext{
${ }^{14}$ Note, however, that this explanation is mathematically not entirely correct as the 'optimal' $S_{0}^{P}$ changes with $T$ as can be seen from the criterion for optimality in equation (20).
} 

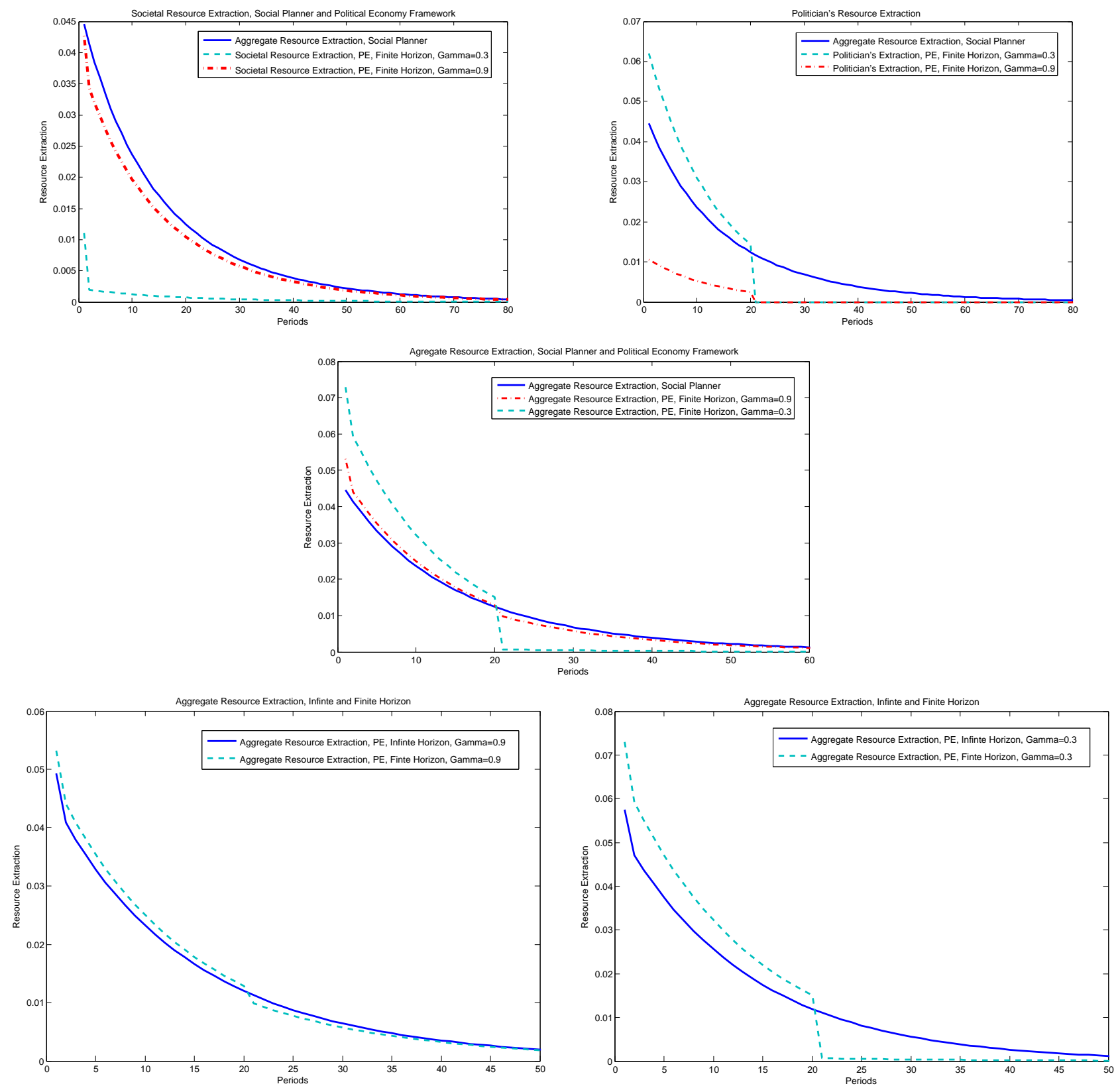

Figure 2: Resource Extraction Paths in the Political Economy Framework with Infinite, Finite Time Horizon and Social Planner Compared

\subsection{Political Succession}

Having considered a finite time horizon for a politician, the question arises what happens after the political leader was removed from office (after or before his time horizon for optimization was reached). Clearly, in case the politician has reached the end of his planning horizon and there is no successor, there is no disruption in the economy's development. The society is on an optimal extraction and production path; a benevolent Social Planner would choose exactly the same consumption and extraction paths for a given 'initial' stock of $S_{T}^{S}=S_{0}^{S}-\int_{s=0}^{T} R_{s}^{S} d s$. 
It seems unreasonable, however, to imagine that after a politician has left the political stage, a benevolent politician or Social Planner will enter the political scene and care for societal welfare only. It is more likely that another not entirely benevolent political elite will come to power. Van der Ploeg (2012) analyzes how a possible regime switch affects the resource depletion of a monopolistic private owner. Our setup is simpler as we focus on the extractive behavior of successive non-benevolent political elites. After a regime change, the new political elite 're-optimizes' with respect to the given capital and resource stock still left in situ at time $T$ : the new political leader optimizes his problem (9) given $K_{T}$ and the resource constraint $S_{T}=\int_{s=T}^{\infty} R_{s} d s$, with $R_{t}=R_{t}^{S}+R_{t}^{P}$.

In Figure 3 we compare the resource extraction in case of an extractive political elite with and without successors. Multiple successions of politicians having a finite time horizon do not result in higher initial resource extraction rates, but have more detrimental effects regarding resource extraction.
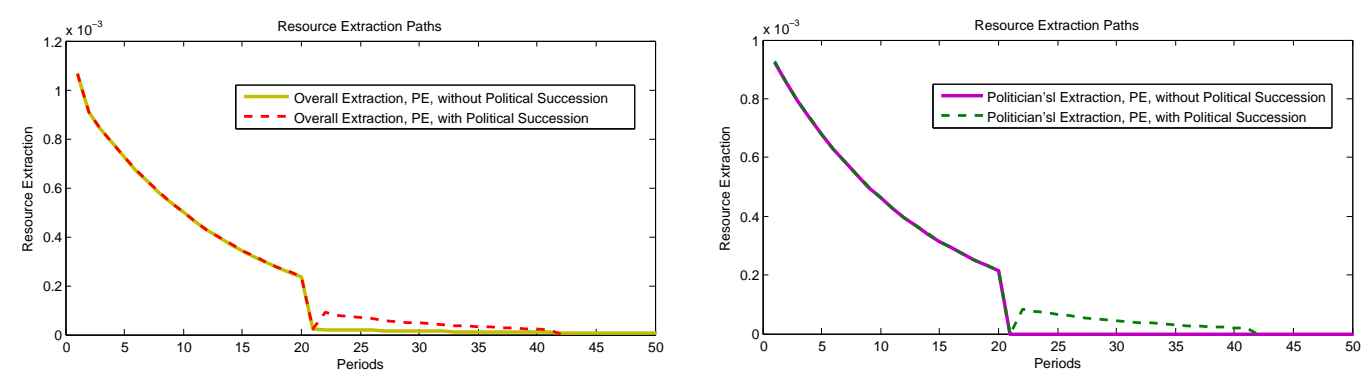

The Politician's and Overall Extraction Paths

Figure 3: Resource Extraction Paths in the Political Economy Framework with and without Political Succession

Also, the politician's time horizon plays a crucial role. The shorter the time horizon, the more extractive does the political leader behave in the beginning. This is especially true for the initial periods, as indicated by Figure 4.
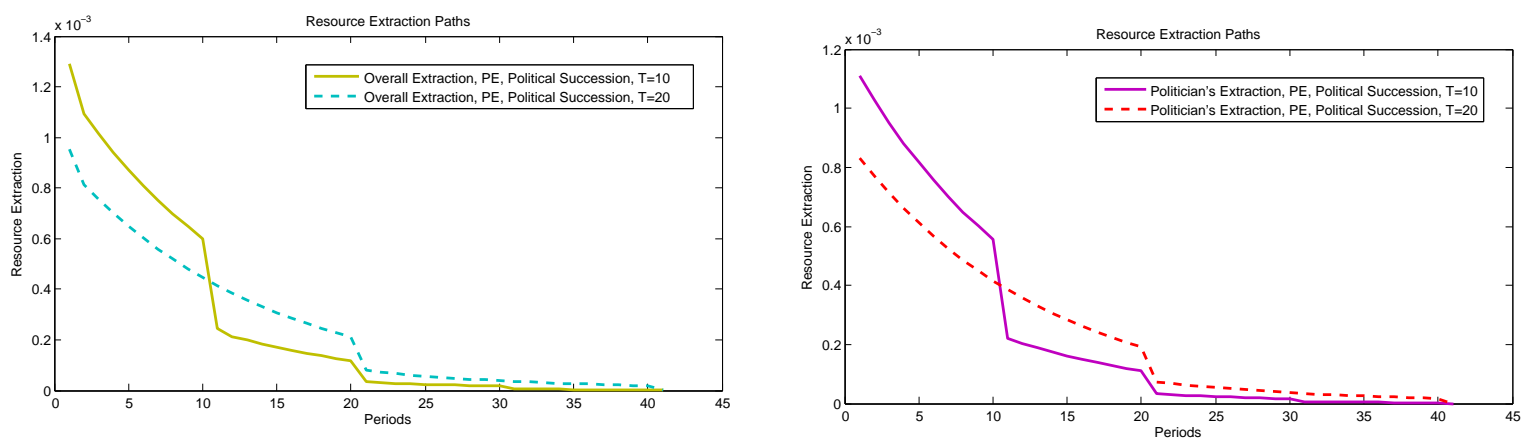

The Politician's and Overall Extraction Paths

Figure 4: Resource Extraction in the Political Economy Framework with Political Succession, Differing Time Horizons 
The higher speed of resource depletion in the first periods due to the politicians' shorter time horizons is not only relevant in welfare terms, but also with respect to climate change. An increased rate of resource usage might disproportionately accelerate the effects of climate change. Some consequences of global warming such as the melting of ice caps, the release of $\mathrm{CO} 2$ from the ocean or methane from perma frost areas have feedback effects on the climate and accelerate global warming even further.

\subsection{Political vs. Decentralizied Markets Economy}

In the previous section we found that the inclusion of political economy features into a model of resource extraction results in higher resource extraction rates than in the pure Social Planner case. The necessary assumption is that the political elite exercises direct control over the resource stock. This assumption holds for various countries. Yet, in other countries, the resource stock is privately owned, but the political elite still strives to maximize its utility. The question is what to prefer if one is concerned about the effects on resource extraction rates: the political elite's direct control over resources or private resource ownership in the presence of rapacious politicians? We explore the ways in which a politician can obtain his private benefits in an economy where he does not directly control the resource stock, and compare the effects of a political leader seeking private benefits via taxation in a decentralized economy with the effects in a political economy framework from Section 2.1 on resource extraction.

In our setting, taxation is not justified by any of the reasons that are usually brought forward such as the aim to remove existing distortions, distributional grounds, or to provide public goods. ${ }^{15}$ Rather, we stick to the assumption of a self-interested political leader or a political elite from Section 2.1, and assume that the tax revenues in each period are appropriated privately by the politician and do not yield any benefits for the society. In Section 2.1, resources yield direct benefits to the political leader. Possible interpretations encompass selling the resources at world markets prices and buying (luxury) goods or arms abroad. Similarly, the political elite uses the tax revenues in the decentralized markets setting for its own benefits. ${ }^{16}$

Moreover, in contrast to the theory of optimal commodity taxation, we assume for simplicity that the government is not concerned with minimizing deadweight loss.

Taxes can be levied on the consumption sector. The most straightforward way of nondistortionary taxation is a lump-sum tax on the private consumers. It is also possible to

\footnotetext{
${ }^{15}$ Surely, the amount of resources used by the society and the politician also implies a certain welfare distribution; here, however, we are referring to the intra-societal welfare distribution which represents no motivation for taxation.

${ }^{16}$ The tax revenues take the form of a share of the economy's (output, capital or consumption) good, or of the resources, depending on the mode of taxation.
} 
tax any of the households' income sources. Taxing labour income would not affect the households' choices as their labour supply is assumed to be fixed. Also, taxation of the resource income and the income from the productive sector does not affect the households' behavior as the resource and productive sector's profits are treated as being exogenous by the households. Thus, the effects of wage, resource and production sector income taxation would resemble the effects of lump-sum taxation on the households: their optimal choices would not be altered. In contrast to lump-sum taxation, however, these taxes would be more distortionary for the economy as they are - depending on the mode of taxation prone to change the optimal choices of the productive and extractive sector respectively. The same holds regarding capital gains taxation.

Resource-based and resource-extracting industries are commonly subject to substantial taxation. ${ }^{17}$ The forms of taxation can be manifold and encompass conventional profit or corporation taxes, as well as royalties, revenue taxes, excess profit taxes, and more complicated tax schemes. As noted before, extractive firms are also affected by interest earnings and capital gains taxes as these alter the real interest rate that the extractive firms operate with. In our numerical exercise, we consider a constant profit tax, i.e. a tax on the profit of a firm, $p_{t} R_{t}$, assuming no extraction costs. ${ }^{18}$

We chose a tax rate such as to obtain a political elite's welfare of 0.055 in the infinite horizon case. Figure 5 shows that in the long run resource extraction is very similar in all modes of taxation and resembles the extraction path in the Social Planner case. The capital stock, investment and consumption paths are shown in the Appendix A.3.3 in Figure A.1 and Figure A.2.

In another numerical exercise, we compare the resource extraction under various (finite) taxation regimes and with the resource extraction in a political economy framework with a politician having a finite time horizon. We find that temporary taxes (which are levied such as to yield a welfare for the politician of 0.01 ) never induce higher resource extraction than in the finite horizon political economy case. In fact, resource extraction is suppressed under the Social Planner's level in some taxation regimes, as can be seen in Figure A.3 in the Appendix A.3.3.

Our numerical exercises have shown that the rapacious, quasi-dictatorial rent extraction on the part of the political leader in Sections 2.1 and 2.2 induces higher resource extraction rates in the initial periods than the introduction of any mode of taxation in the

\footnotetext{
${ }^{17}$ Daubanes and Lasserre (2012) note that, under standard assumptions in the literature on nonrenewable resource extraction and the optimum commodity taxation, an exhaustible resource should be taxed irrespective of its demand elasticity and the demand elasticity of other commodities. Furthermore, it should be taxed higher than other commodities with the same demand elasticity and the tax rate should vary over time.

${ }^{18}$ Yet, in case the tax is deemed finite, it might in some cases induce resource owners to postpone extraction until the expiration date of the tax. A tax which affects the resource owners but does not induce them to postpone extraction is a tax on interest earnings and capital gains, for instance.
} 


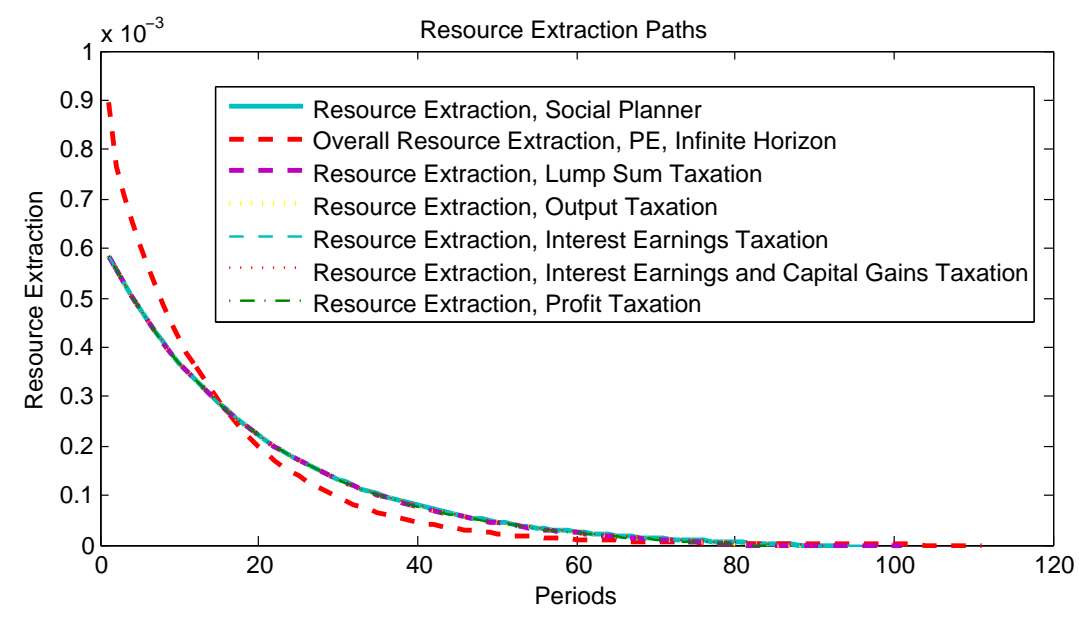

Figure 5: Resource Extraction in the PE and in the Various Taxation Cases

decentralized economy models. For some of the taxation modes this result hinges on the assumption of constant tax rates. ${ }^{19}$

\section{Endogenous Political Economy Framework}

In this section we will introduce a discrete time model where the weight $\gamma$ that the political leader attaches to the welfare of society is endogenized, and the political leader's probability of staying in power depends on social welfare. Furthermore, we show how the politician's discount rate $\delta$, which is higher than the society's rate of time preference $\rho$, can be derived with the help of the probability $\pi_{t}$ of staying in power (Robinson, Torvik, and Verdier, 2006). The aim of this section is to motivate the assumptions about the form of the political leader's welfare function made in Section 2.1.

The political leader in this setup is supposed to be fully self-interested. He shows no direct concerns for society which contrasts with approaches taken in models with politicians' partisan preferences (Tabellini and Alesina, 1990; Alesina and Tabellini, 1987; Persson, Roland, and Tabellini, 2007). Similar to Sections 2.1 to 2.3, we assume that the resource stock is not privately owned, but rather that the political elite determines the amount of resources extracted each period and decides upon its use. On the one hand, the political leader might use the resource for the benefit of society. Providing the productive sector with resources by deciding on the amount of $R_{t}^{S}$ is the only policy tool the politician has at hand. On the other hand, he might use resources for his own benefit, to enhance his own

\footnotetext{
${ }^{19}$ It is possible, however, to reproduce the resource extraction path in the case of a rapacious politician also in the decentralized market case. Introducing a tax scheme which is increasing in time, for instance, would speed up extraction in the initial periods. Yet, the resulting tax revenue path would be most probably increasing which does not reflect the dictator's utility path whose welfare constitutes the benchmark for setting the tax rate in the decentralized market case.
} 
consumption $C_{t}^{P}$ as described in Section 2.1, by buying luxury goods abroad, for instance, purchasing arms in order to suppress domestic opposition, or for white elephant projects.

In a setting where the political leader would be certain to stay in office for all three periods, he would not have any incentives to supply the society with resources. Yet, in our setting, he stays in power only with a certain probability. As argued in Section 2.1, this is a consequence of recurrent elections in democratic regimes. But also in more autocratic regimes the political elite is not uncontested, especially in the case of a resource abundant country (Casellli, 2006). Domestic opposition might try to challenge the incumbent politician by staging a coup for instance.

The probability of staying in power is supposed to be a function of social welfare in the preceding period only, i.e. the probability of being in office in period $t+1$ can be denoted as $\pi_{t}\left(u_{S}\left(C_{t}^{S}\right)\right) .{ }^{20}$ The higher the level of society's satisfaction or utility, the higher the political leader's reelection probability. This idea can be found in Ravetti, Sarr, and Swanson (2012), where the authors consider a dictator having the implicit property rights in the resources of the state. The resource flows can be consumed immediately or invested in the productive capacity of the economy in their setting. Also, the ruler can affect the length of his tenure by investing in social betterment (consumption), though the uncertainty regarding a possible end of his regime in each period remains.

The society in our setting is politically not forward-looking. Rather, we assume myopic behavior: the 'popularity' of a politician within the society determines his chances to be reelected or, in general, to stay in office. The level of his 'popularity' among the electorate depends on the level of well-being of the society. This idea forms the basis of opportunistic models of political behavior (Besley, 1977; Drazen and Eslava, 2006), which predict higher governmental spending prior to elections. Empirical studies seem to confirm the existence of political business cycles (Schuknecht, 1996; Block, 2002). Brender and Drazen (2005) find empirical evidence in a large cross-section of countries in the case of 'new' democracies, in both developed and less developed countries. Politicians seem to believe that higher spending increases their probability of being reelected. They suppose that higher governmental expenditures augment the welfare of the society, and that the society as their electorate bases its voting decision on the government's ability to provide societal well-being during the time preceding the elections. Hence, from the viewpoint of the political elite, society is not forward-looking and acts myopic. This provides them with an incentive to care for social well-being in order to rise their probability of being reelected and enjoy benefits from holding office for one more period.

\footnotetext{
${ }^{20}$ In Robinson, Torvik, and Verdier (2006) who try to find political foundations of the resource curse in a two period probabilistic model, the politician's reelection probability depends on the transfers to citizens and employment in the public sector.
} 
As mentioned above, in this simple setup the only tool the politician has at hand to influence the well-being of society is to supply the productive sector with a certain amount of resources, $R_{t}^{S}$, every period. As in Section 2, the resource provides the politician with private benefits or 'consumption', i.e. $R_{t}^{P}=C_{t}^{P}$. The total resource extraction in every period equals $R_{t}=R_{t}^{P}+R_{t}^{S}$; hence, the amount of resources destined for societal production signifies an immediate loss of the politician's consumption and his instantaneous utility. Consequently, at the beginning of every period, the politician faces a trade-off between his own consumption in the given period, and the possiblity of increasing his chances of consumption in the next periods. Also, assuming that the politician's utility function satisfies the Inada conditions, his incentive to stay in office for the entire time horizon is substantial as he cannot 'store' the resource and hence needs to 'consume' it immediately, i.e. in the period of extraction. Accroaching the highest amount of resources possible in the first period is thus never an optimal strategy. Another simplifying assumption is that the politician's consumption level after leaving office is zero. Yet, such a scenario is rather improbable: history provided us with examples of dictators who, for instance, settled down abroad and enjoyed a good life. Yet, as the maximization problem at hand solely focuses on the politician's utility derived from accroaching the non-renewable resource, setting the consumption of this resource to zero is justifiable after he lost the possibility to appropriate part of the resource for himself.

The functional form of the probability of staying in power and its elasticity with respect to social welfare are central characteristics of the political economy framework. They determine the extent to which the politician cares about society, i.e. the weight $\gamma$ from Sections 2.1 to 2.3. The functional forms and their corresponding sensitivities to social welfare are associated with certain political regimes. It seems sensible that the reelection probability in democratic regimes exhibits a higher elasticity with regard to societal welfare than in more autocratic regimes.

Furthermore, there is a maximum amount of resources that might be depleted in the finite time horizon due to physical constraints. Whether the entire existing resource stock is thereby depleted or not is not relevant in this finite time setting. We denote this maximum amount that is available for extraction at the beginning of the first period as $S_{1}$. The resource constraint thus reads

$$
S_{t+1}=S_{t}-R_{t}^{S}-R_{t}^{P} \quad \text { and } \quad S_{1}=\sum_{t=1}^{T}\left(R_{t}^{S}+R_{t}^{P}\right)
$$

However, the political leader has no incentive to care for the society in the last period; he might just appropriate what is left of the resource, i.e. $R_{T}^{P}=S_{1}-\sum_{t=1}^{T-1}\left(R_{t}^{P}+R_{t}^{S}\right)$. In 
our setting the society is very myopic. When deciding about reelecting the political leader after the second period, it does not consider this danger of affliction in the last period as a consequence of the politician's rapaciousness, but bases its decision solely on the utility obtained in the second period. Yet, if we allow for a small amount of foresight, it does not seem very plausible that the society will not account for this possibility of penury in the third period. This might drastically lower the political elite's probability of staying in power. On the other hand, it seems unlikely that the politician would not anticipate the effect of his rapacious behavior in the last period on the electoral behavior and thus would not act according to a significantly lower probability of holding onto power. This would alter the probabilities of staying in power that the political leader accounts for in his maximization problem. ${ }^{21}$ Yet, given the completely myopic decision making of the society, no remedy for this problem is not necessary for now, and the political leader does not provide any resources to the society in the last period.

In order to analyze the political leader's decision making process we need to consider his utility maximization problem separately at the beginning of the first and then at the beginning of the second period.

At the beginning of the first period, the political leader maximizes his utility over the entire time horizon as depicted in (22). The politician thus decides on the amount of resources destined for his own benefit and for the benefit of society in the first and in the second period. At the end of the first period elections are held. Ex ante, the political leader can influence his probability of staying in power by supplying resources to the society. He decides which amount of resources to supply to the society in the first and the second period. Given that his reelection at the end of the first period was successful, the political leader is faced with another maximization problem at the beginning of period 2 . The first period's maximization problem reads:

$$
\begin{aligned}
& \max _{C_{t}^{P}, R_{t}^{S}, R_{t+1}^{P}} \sum_{t=1}^{T}\left(\frac{1}{1+\rho}\right)^{t-1}\left\{\pi_{t-1}\left(u_{S}\left(C_{t-1}^{S}\right)\right) u_{P}\left(C_{t}^{P}\right)\right\}, \\
& \text { s.t. (21) holds, } C_{t}^{S}=K_{t}^{\alpha} R_{t}^{S^{\beta}}-\left(K_{t+1}-K_{t}\right) \text { and } C_{t}^{P}=R_{t}^{P},
\end{aligned}
$$

with $\pi_{0}=1$ and $\pi_{t} \in(0,1)$ for $t=1, \ldots, T$, and an economy producing according to a Cobb-Douglas production function $K_{t}^{\alpha} R_{t}^{S^{\beta}} L_{t}^{1-\alpha-\beta}$, with labour normalized to one.

\footnotetext{
${ }^{21}$ To avoid this feedback induction on the maximization problem, one could assume, for instance, that the political leader can commit by law or constitution to a certain minimum level of resource supply for the society in every period, $R_{\min }^{S}$. The political leader will not provide any additional resources than $R_{\min }^{S}$ for the society in the third period; hence $R_{T}^{S}$ is not a decision variable. We can thus rewrite the resource constraint in the following way: $S_{1}-R_{\min }^{S}=S_{1}^{\text {new }}=\sum_{t=1}^{T} R_{t}^{P}+\sum_{t=1}^{T-1} R_{t}^{S}$, with $R_{\min }^{S}=R_{T}^{S}$.
} 
Using the first order conditions (B.2) in the Appendix B, we obtain the following proposition:

Proposition 2. The consumption path of the politician evolves in the following way

$$
\frac{C_{t+1}^{P^{-1 / \psi}}}{C_{t}^{P_{t}^{-1 / \psi}}}=\frac{(1+\rho) \pi_{t-1}}{\pi_{t}}
$$

If $\pi_{t}<\pi_{t-1}$, then we can define $\frac{\pi_{t}\left(C_{t}^{S}\right)}{\pi_{t-1}\left(C_{t-1}^{S}\right)(1+\rho)} \equiv \frac{1}{1+\delta}$, and $\delta>\rho$ as in section 2 .

Proof. See Appendix B.

The uncertainty about the politician being in power in the next period, i.e. $\pi \in(0,1)$ is an addition to his discount factor. It implies higher extraction levels than in a Social Planner's optimum. ${ }^{22}$ Note that for expression (23) to characterize a subgame perfect path for the politician, it must hold that $\pi_{t-1}=1 .{ }^{23}$ The reason is that at the beginning of the second period, for instance, after having been successfully reelected, the political leader faces a 'new' optimization problem:

$$
\max _{C_{t}^{P}, R_{t}^{S}, R_{t+1}^{P}} \sum_{t=2}^{T}\left(\frac{1}{1+\rho}\right)^{t-1}\left\{\pi_{t-1}\left(u_{S}\left(C_{t-1}^{S}\right)\right) u_{P}\left(C_{t}^{P}\right)\right\}, \quad \text { s.t. } \quad S_{2}=\sum_{t=2}^{T} R_{t}^{P}+R_{t}^{S}
$$

with $\pi_{1}=1$ and $\pi_{t} \in(0,1)$ for $t=2$ and $S_{2}=S_{1}-R_{1}^{P}-R_{1}^{S}$ being the maximum amount to be depleted at the beginning of this second period. The optimal choices of the politician at the beginning of the first period do change if one considers his optimization problem at any later stage. The reason is that in period $t$ the probability of him reaching period $t, \pi_{t-1}$, is always 1 .

The resulting resource extraction paths are shown in Figure 6 together with the politician's endogenous probability of staying in power. In the numerical example we chose the probability to be a logistic function of the society's consumption, i.e. $\pi=\frac{e^{C^{S}}}{1+e^{C^{S}}}$. The resulting re-election probabilities range between 0.91 and 0.67 . The second graph of Figure 6 displays the social consumption levels and the resulting probability of staying in power. Social consumption is the consequence of the politician's choice of his own and society's resource usage. Both, the social and the politician's resource usage is decreasing. The politician's resource extraction path results from his period to period optimization in the case of no commitment. The corrresponding resource stock equals $S_{0}=25.37$.

\footnotetext{
${ }^{22}$ The idea that lifetime uncertainty affects the rate at which felicity is discounted can also be found in the Blanchard-Yaari model. Yet, to obtain a higher discount factor $\delta>\rho$ in their continuous time model, one has to assume a specific functional form for the probability to be alive at time $\tau$ : $\phi(\tau)=\mu e^{-\mu \tau}$, with $\phi(\tau)$ being the probability of death at date $\tau$ and $\mu$ being the contribution to the discount factor
} 

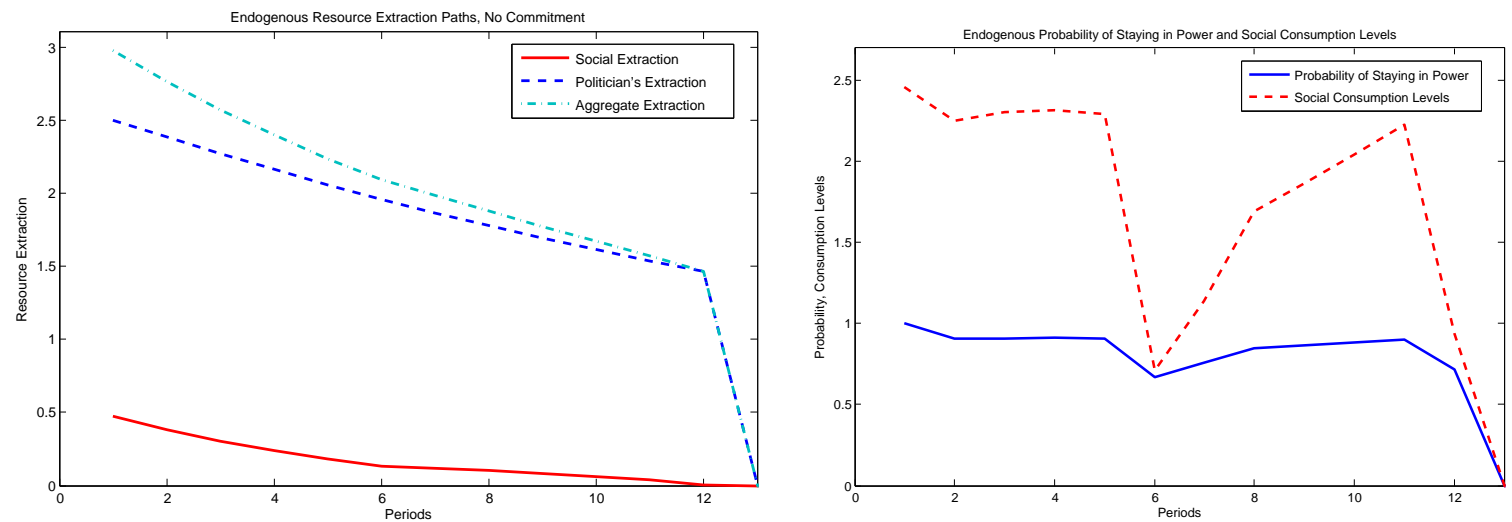

Figure 6: Societal, Politician's and Aggregate Resource Extraction in the Endogenous Political Economy Framework; Social Consumption Levels and Endogenous Probability of Staying in Power

Knowing the endogenous probability of staying in power, we can compute the politician's implicit discount rate for every period. Figure 7 displays this close relationship. We see that a lower re-election probability immediately translates into a higher implicit discount rate. Higher uncertainty of staying in power in the next periods does not translate into lower consumptions level of the politicians. This would be the case if the politician could commit to his resource consumption path ex ante. In a subgame-perfect equilibrium, however, the politician decides in period $t$ about his consumption $C_{t}^{P}$, given the fact that he has been already re-elected. It does translate, however, in lower social consumption and hence in a lower implicit social weight $\gamma$, as is shown below. In our example, the discount rates range from 0.16 in the beginning and reach a peak of 0.565 , before they decline and rise again in the very last period.

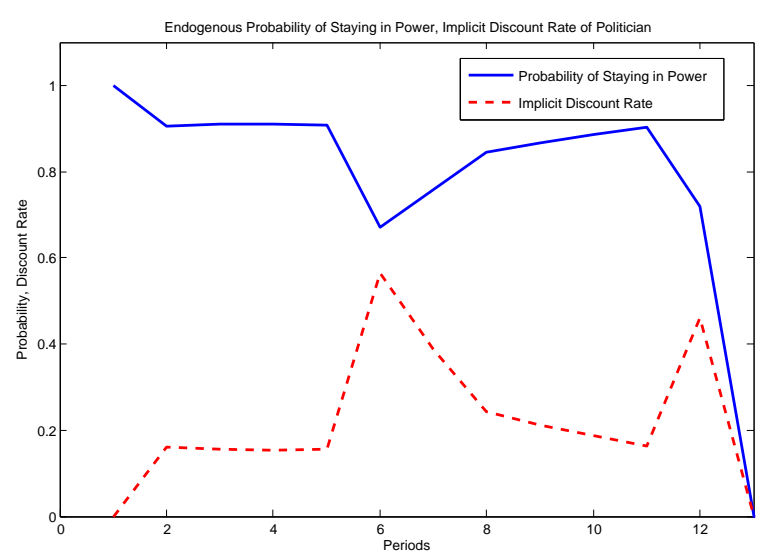

Figure 7: Endogenous Probability of Staying in Power and the Politician's Discount Factor and Discount Rates

Given the functional form of the re-election probability and the politician's initial $\delta=\rho+\mu$.

${ }^{23}$ This is a very realistic case of no commitment by the policitian to a certain consumption path. 
consumption determined by an optimally chosen $\mu_{1}$, we can translate the political elite's maximization problem (22) into the exogenous maximization in section 2.1. Let us suppose that in both the exogenous and the endogenous model specification, the politician chooses the same initial consumption level $C_{t}^{P}$. Considering the first period's resource shadow price, we equalize the first order conditions from section 2.1 and (B.2) (assuming the initial period in the model specification of section 2.1 to be period 1), and simplify to obtain

$$
\frac{1-\gamma_{t}}{\gamma_{t}}=\frac{\pi_{t-1}(1+\rho)\left(\frac{1}{1+\rho}\right)^{t-1}}{\frac{\partial \pi_{t}}{\partial C_{t}^{S}}\left(\frac{1}{1+\delta}\right)^{t-1} u_{P}\left(\frac{\pi_{t}}{\mu_{0}(1+\rho)^{t+1}}\right)}
$$

where $\pi_{t-1}=1$. Given the functional form of $\pi$, all expressions on the right hand side are known in the respective periods. It is thus easy to back out the corresponding section 2.1 's $\gamma$ for the first period. Similarly, the weight for the well-being of the society in the second period can be determined.

For this to be done, the exact functional form of the probability of staying in power needs to be defined. Of course a plethora of different functional specifications is possible. One could think of a discrete probability distribution where at a number of countable utility thresholds reelection probability reaches a certain level, or a case where the probability of staying in power is of the logit form. We continue to assume that the probability is a logistic function of the society's consumption.

We calculated the implicit $\gamma_{t}$ 's that would correspond to a model as presented in section 2. Figure 8 displays the social weights employed by the politician. The social weights decline (non-monotonically) over time; in our example they range from 0.055744 in the beginning to 0.00011143 in the last period and correspond with the low level of social resource extraction.

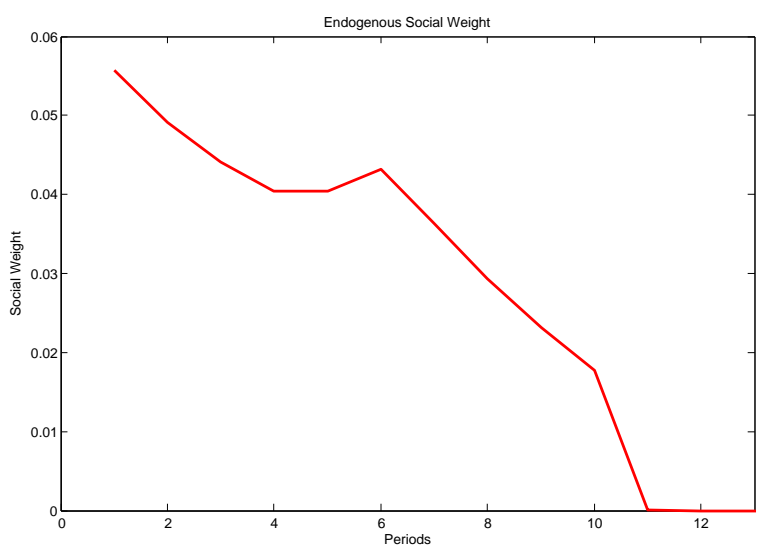

Figure 8: Social Weights Implicitly Employed by the Politician and his Implicit Discount Factor 


\section{Conclusion}

Augmenting the optimization problem of a Social Planner by an additional private utility term for the political leader generally results in initially higher resource extraction rates. This is due to the politician being characterized by a higher discount rate than the society's rate of pure time preference and a finite time horizon, and directly accroaching a share of the resources for himself.

In a decentralized markets economy, the political elite's revenue can be obtained in an intertemporally consistent way by introducing a constant output, consumer lump-sum, interest earnings, and a combination of interest earnings and capital gains tax. Our numerical example shows that those modes of taxation induce extraction rates which are equal or lower than those obtained in the Social Planner optimum. Thus, taxation is a way of obtaining revenues for the politician that does not result in excessive resource extraction rates like those obtained in the case when the politician can directly accroach resources.

Finally, the choice of the political economy features is motivated by endogenizing the political elite's higher discount rate and the weight of the society in the political leader's welfare function. Due to uncertainty of staying in power, the political leader discounts the future more than the society. Furthermore, his 'staying-in-power' or 're-election' probability depends on social welfare and induces the politician to also account for social well-being. The chosen parameters yield low weights of the societal welfare which fall non-monotonically further over time.

Further work on the political economy framework of resource depletion could focus on the endogenized version of the model. The politician's incentives can be analyzed further by employing different functional forms for the probability of staying in power depending on the (democratic) inclusiveness of the regime. This would give us a more detailed picture of the consequences for social welfare and non-renewable resource extraction in countries with state-owned resouces.

\section{References}

Alesina, A., and G. Tabellini (1987): "A Positive Theory of Fiscal Deficits and Government Debt in a Democracy," NBER Working Papers 2308, National Bureau of Economic Research, Inc.

Benchekroun, H., and C. Withagen (2011): "The optimal depletion of exhaustible resources: A complete characterization," Resource and Energy Economics, 33(3), 612636. 
Besley, T. (1977): "Electoral Strategy and Economic Policy," Discussion paper.

Block, S. A. (2002): "Political business cycles, democratization, and economic reform: the case of Africa," Journal of Development Economics, 67(1), 205 - 228.

Brender, A., And A. Drazen (2005): "Political budget cycles in new versus established democracies," Journal of Monetary Economics, 52(7), 1271-1295.

Bulte, E., and R. Damania (2008): "Resources for Sale: Corruption, Democracy and the Natural Resource Curse," The B.E. Journal of Economic Analysis \& Policy, 8(1), 5 .

Casellli, F. (2006): "Power Struggles and the Natural Resource Curse," Discussion paper, London School of Economics.

Crommelin, M., And A. R. Thompson (1977): Mineral Leasing As an Instrument of Public Policy. Vancourver: University of British Columbia Press.

Dasgupta, P. (2001): "Valuing Objects and Evaluating Policies in Imperfect Economies," Economic Journal, 111(471), C1-29.

Dasgupta, P., G. Heal, and J. E. Stiglitz (1981): "The Taxation of Exhaustible Resources," NBER Working Papers 0436, National Bureau of Economic Research, Inc.

Dasgupta, P. S., and G. M. Heal (1979): Economic Theory and Exhaustible Resources, no. 9780521297615 in Cambridge Books. Cambridge University Press.

Daubanes, J., and P. Lasserre (2012): "Optimum Commodity Taxation with a NonRenewable Resource," CIRANO Working Papers 2012s-04, CIRANO.

Deacon, R. (2003): "Dictatorship, Democracy, and the Provision of Public Goods," University of California at Santa Barbara, Economics Working Paper Series 11925, Department of Economics, UC Santa Barbara.

Drazen, A., And M. Eslava (2006): "Pork Barrel Cycles," NBER Working Papers 12190, National Bureau of Economic Research, Inc.

Frankel, J. A. (2010): "The Natural Resource Curse: A Survey," NBER Working Papers 15836, National Bureau of Economic Research, Inc.

Gaitan, B. S., R. S. Tol, and I. H. Yetkiner (2006): "The Hotelling's Rule Revisited in a Dynamic General Equilibrium Model," in Proceedings of the Conference on Human and Economic Resources, Papers of the Annual IUE-SUNY Cortland Conference in Economics, pp. 213-238. Izmir University of Economics. 
Grossman, G. M., and E. Helpman (1996): "Electoral Competition and Special Interest Politics," The Review of Economic Studies, 63(2), pp. 265-286.

(1998): "Intergenerational Redistribution with Short-Lived Governments," The Economic Journal, 108(450), pp. 1299-1329.

Gylfason, T. (2001): "Natural resources, education, and economic development," European Economic Review, 45(4-6), 847-859.

Hamilton, K., and M. Clemens (1999): "Genuine Savings Rates in Developing Countries," The World Bank Economic Review, 13(2), 333-356.

Hamilton, K., G. Ruta, and L. Tajibaeva (2005): "Capital accumulation and resources depletion - a Hartwick rule counterfactual," Policy Research Working Paper Series 3480, The World Bank.

KARP, L., And D. M. Newbery (1991): "Optimal tariffs on exhaustible resources," Journal of International Economics, 30(3-4), 285-299.

Knack, S., And P. Keefer (1995): "Institutions And Economic Performance: CrossCountry Tests Using Alternative Institutional Measures," Economics and Politics, 7(3), $207-227$.

La Porta, R., F. Lopez-de Silanes, A. Shleifer, and R. Vishny (1999): "The Quality of Government," Journal of Law, Economics and Organization, 15(1), 222-79.

Leite, C., And J. Weidmann (1999): "Does Mother Nature Corrupt - Natural Resources, Corruption, and Economic Growth," IMF Working Papers 99/85, International Monetary Fund.

Mehlum, H., K. Moene, and R. TorviK (2006): "Institutions and the Resource Curse," Economic Journal, 116(508), 1-20.

Pearce, D., K. Hamilton, and G. Atkinson (1996): "Measuring sustainable development: progress on indicators," Environment and Development Economics, 1(01), 85-101.

Persson, T., G. Roland, and G. Tabellini (2007): "Electoral Rules and Government Spending in Parliamentary Democracies," Levine's Working Paper Archive 321307000000000880 , David K. Levine.

Ramanathan, V. (1980): "Climatic effects of anthropogenic trace gases," in Interactions of Energy and Climate, ed. by W. Bach, T. Pankrath, and J. Williams. D. Reidel Publishing Co. 
Ramsey, F. P. (1928): "A Mathematical Theory of Saving," The Economic Journal, 38(152), pp. 543-559.

RAO, N. S. (2010): "Taxation and the Extraction of Exhaustible Resources," MITCEEPR (Series) 10-006, MIT.

Ravetti, C., M. Sarr, and T. Swanson (2012): "Nations Aiding and Abetting the Looting of Nations," Discussion paper.

Robinson, J. A., And R. Torvik (2005): "White elephants," Journal of Public Economics, 89(2-3), 197-210.

Robinson, J. A., R. Torvik, and T. Verdier (2006): "Political foundations of the resource curse," Journal of Development Economics, 79(2), 447-468.

Sachs, J. D., And A. M. WARner (1995): "Natural Resource Abundance and Economic Growth," Working Paper 5398, National Bureau of Economic Research.

(2001): "The curse of natural resources," European Economic Review, 45(4-6), $827-838$.

Schuknecht, L. (1996): "Political Business Cycles and Fiscal Policies in Developing Countries," Kyklos, 49(2), 155-170.

Tabellini, G., and A. Alesina (1990): "Voting on the Budget Deficit," The American Economic Review, 80(1), pp. 37-49.

Tornell, A., And P. R. Lane (1999): "The Voracity Effect," The American Economic Review, 89(1), pp. 22-46.

VAn Der Ploeg, F. (2010): "Natural Resources: Curse or Blessing?," Discussion paper. (2011): "Rapacious Resource Depletion, Excessive Investment and Insecure Property Rights: A Puzzle," Environmental \&f Resource Economics, 48(1), 105-128.

Van der Ploeg, F. (2012): "Resource Wars and Confiscation Risk," Discussion paper.

Withagen, C. (2012): "Nash and Stackelberg cartel-versus-fringe models," Discussion paper, Department of Spatial Economics, VU University Amsterdam. 


\section{A Derivations}

\section{A.1 Political Economy Framework}

In section 2.1, the first order conditions for the present value Hamiltonian (7) read as follows: The first order conditions for the Hamiltonian read as follows:

$$
\begin{aligned}
\frac{\partial H}{\partial C_{t}^{P}} & =e^{-\delta t}(1-\gamma) u_{P}^{\prime}-\mu(t)=0 \\
\frac{\partial H}{\partial C_{t}^{S}} & =\gamma e^{-\rho t} u_{S}^{\prime}\left(C_{t}^{S}\right)-\lambda(t)=0 \\
\frac{\partial H}{\partial R_{t}^{S}} & =\lambda(t) \beta K_{t}^{\alpha} R_{t}^{S^{\beta-1}} L_{t}^{1-\alpha-\beta}-\mu(t)=0 \\
\frac{\partial H}{\partial K_{t}} & =-\dot{\lambda}(t)=\lambda(t) \alpha K_{t}^{1-\alpha} R_{t}^{S^{\beta}} L_{t}^{1-\alpha-\beta} \\
\frac{\partial H}{\partial S_{t}} & =-\dot{\mu}(t)=0
\end{aligned}
$$

Furthermore, the following transversality condition should be satisfied.

$$
\lim _{t \rightarrow \infty}\left[e^{-\rho t} \lambda(t) K(t)+e^{-\delta t} \mu(t) S(t)\right]=0
$$

We have $e^{-\delta t}(1-\gamma) u_{P}^{\prime}-\mu(t)$; total differentiation yields:

$$
\dot{\mu}(t)=-\delta e^{-\delta t}(1-\gamma) u_{P}^{\prime}+e^{-\delta t}(1-\gamma) u_{P}^{\prime \prime} \dot{C}_{t}^{P}
$$

As $-\dot{\mu}(t)=0$, we have that the politician's consumption path evolves in the following way:

$$
\frac{\dot{C}_{t}^{P}}{C_{t}^{P}}=-\delta \psi
$$

Total differentiation of $\lambda(t)$ gives:

$$
0=-\dot{\lambda}(t)-\rho e^{-\rho t} \gamma C_{t}^{S^{-1 / \theta}}+e^{-\rho t} \gamma\left(-\frac{1}{\theta} C_{t}^{S^{-1 / \theta-1}}\right) \dot{C}_{t}^{S}
$$

which can be rewritten as

$$
\dot{\lambda}(t)=\left[-\rho-\frac{1}{\theta} \frac{\dot{C}_{t}^{S}}{C_{t}^{S}}\right] e^{-\rho t} \gamma C_{t}^{S^{-1 / \theta}}
$$

This yields the following equation for the development of the multiplier:

$$
\frac{\dot{\lambda}(t)}{\lambda(t)}=-\rho-\frac{1}{\theta} \frac{\dot{C_{t}^{S}}}{C_{t}^{S}}=-r_{t}
$$


This characterizes the evolution of the societal consumption:

$$
\frac{\dot{C}_{t}^{S}}{C_{t}^{S}}=\theta\left(r_{t}-\rho\right)
$$

The shadow price of the resource equals $q_{t}=\beta K_{t}^{\alpha} R_{t}^{S^{\beta-1}} L_{t}^{1-\alpha-\beta}=\frac{1-\gamma}{\gamma} e^{-(\delta-\rho) t} \frac{u_{P}^{\prime}}{u_{S}^{\prime}}$. Differentiating this yields:

$$
\dot{q}_{t}=\frac{1-\gamma}{\gamma}\left[-(\delta-\rho) e^{-(\delta-\rho) t} \frac{u_{P}^{\prime} u_{S}^{\prime}}{\left(u_{S}^{\prime}\right)^{2}}+e^{-(\delta-\rho) t} \frac{u_{P}^{\prime \prime} \dot{C}_{t}^{P} u_{S}^{\prime}}{\left(u_{S}^{\prime}\right)^{2}}-e^{-(\delta-\rho) t} \frac{u_{P}^{\prime} u_{S}^{\prime \prime} \dot{C}_{t}^{S}}{\left(u_{S}^{\prime}\right)^{2}}\right]
$$

Assuming the standard CRRA functional form for the utility function and writing out the above yields:

$$
\begin{gathered}
\dot{q}_{t}=\frac{1-\gamma}{\gamma} e^{-(\delta-\rho) t}\left[-(\delta-\rho) \frac{C_{t}^{P^{-1 / \psi}}}{C_{t}^{S^{-1 / \theta}}}-\frac{1}{\psi} \frac{C_{t}^{P^{-1 / \psi}} \dot{C}_{t}^{P}}{C_{t}^{S^{-1 / \theta}} C_{t}^{P}}+\frac{1}{\theta} \frac{C_{t}^{P^{-1 / \psi}} \dot{C}_{t}^{S}}{C_{t}^{S^{-1 / \theta}} C_{t}^{S}}\right] \\
\dot{q}_{t}=\frac{1-\gamma}{\gamma} e^{-(\delta-\rho) t} \frac{C_{t}^{P^{-1 / \psi}}}{C_{t}^{S^{-1 / \theta}}}\left[-(\delta-\rho)-\frac{1}{\psi} \frac{\dot{C}_{t}^{P}}{C_{t}^{P}}+\frac{1}{\theta} \frac{\dot{C}_{t}^{S}}{C_{t}^{S}}\right]
\end{gathered}
$$

As $\frac{1-\gamma}{\gamma} e^{-(\delta-\rho) t} \frac{C_{t}^{P^{-1 / \psi}}}{C_{t}^{S^{-1 / \theta}}}=q_{t}$, we can rewrite the expression above as

$$
\frac{\dot{q}_{t}}{q_{t}}=\left[-(\delta-\rho)-\frac{1}{\psi} \frac{\dot{C}_{t}^{P}}{C_{t}^{P}}+\frac{1}{\theta} \frac{\dot{C}_{t}^{S}}{C_{t}^{S}}\right]
$$

Having that $\frac{\dot{C}_{t}^{P}}{C_{t}^{P}}=-\delta \psi$ and that $\frac{\dot{C}_{t}^{S}}{C_{t}^{S}}=\theta\left(r_{t}-\rho\right)$, the expression above reduces to the standard Hotelling rule:

$$
\frac{\dot{q}_{t}}{q_{t}}=r_{t}
$$

Proof of Proposition 1. The social consumption and extraction levels in the presence of the political leader differ from the pure Social Planner case, as the initial values of the multipliers, $\lambda_{0}$ and $\mu_{0}$, need to change in order to sustain a new equilibrium. We use the subscript $P E F$ for multiplier values in the political economy framework, and $S P$ for the Social Planner economy. Introducing a politician into a Social Planner model results in $\mu_{0}^{P E F}>\mu_{0}^{S P}$ in order to make the resource more scarce. Also, $\lambda_{0}^{P E F}<\lambda_{0}^{S P}$ in order to compensate for the initial consumption levels of the society being depressed by the presence of the politician.

For initial aggregate resource depletion in the political economy framework to be higher 
than resource extraction in the Social Planner case, it needs to hold:

$$
(1-\gamma) \psi \delta S_{0}^{P}+\left(\lambda_{0}^{P E F} \beta K_{0}^{\alpha} \psi \delta S_{0}^{P}\right)^{\frac{1}{1-\beta}}=\frac{1-\gamma}{\mu_{0}^{P E F}}+\left(\frac{\lambda_{0}^{P E F} \beta K_{0}^{\alpha}}{\mu_{0}^{P E F}}\right)^{\frac{1}{1-\beta}}>\left(\frac{\lambda_{0}^{S P} \beta K_{0}^{\alpha}}{\mu_{0}^{S P}}\right)^{\frac{1}{1-\beta}}
$$

As mentioned before, $\mu_{0}^{P E F}>\mu_{0}^{S P}$ and $\lambda_{0}^{P E F}<\lambda_{0}^{S P}$. Yet, due to its first term, the inequality (A.3) holds for all (sensible) parameter values employed so far. However, parameter values might exist for which the inequality (A.3) does not hold for very high values of $\gamma$ combined with still relatively low $S_{0}^{P}$.

\section{A.2 Decentralized Markets Economy}

\section{A.2.1 Decentralized Markets Economy without Taxation}

We show the first order conditions corresponding to the households' and extractive firms' problems in section 2.4. The first order conditions for the households' and the firms' maximization problems in the presence of taxation are derived in a similar way and are not explicated separately. We look at the simplest case of a competitive private ownership economy without taxation. The households own the capital stock and are the recipients of the resource revenues as they are simultaneously the owners of the resource extractive sector. The representative household maximizes the following intertemporal welfare function:

$$
\int_{s=0}^{\infty} u\left(C_{s}\right) e^{-\rho s} d s
$$

subject to the following budget constraint:

$$
C_{t}+\dot{W}_{t}=r_{t} W_{t}+\pi_{t}^{Y}+\pi_{t}^{R}+\pi_{t}^{L}
$$

where $W_{t}$ represents the household's wealth or assets, $\pi_{t}^{Y}, \pi_{t}^{R}, \pi_{t}^{L}$ denote the household's profits it gets from the productive and the resource sector, and its labour income respectively. As $\pi_{t}^{Y}=Y-r_{t} K_{t}-p_{t} R_{t}-w_{t} L, \pi_{t}^{R}=p_{t} R_{t}$ and $\pi_{t}^{L}=w_{t} L_{t}$, with $p_{t}$ being both the consumer price and the royalty (in absence of any taxation or distortions) of one unit of resource, and $L_{t}=1$ assuming inelastic labour supply, (A.5) can be rewritten as:

$$
\dot{W}_{t}=Y_{t}-C_{t}
$$

This is exactly the equation for capital evolution; the household's wealth equals the economy's capital stock. The Hamiltonian for this problem looks as follows:

$$
H \equiv u\left(C_{t}\right)+\lambda\left(r_{t} W_{t}+\pi_{t}^{Y}+\pi_{t}^{R}+\pi_{t}^{L}\right)
$$


The first order conditions and the transversality condition for the Hamiltonian in (A.7) read as follows:

$$
\begin{aligned}
\frac{\partial H}{\partial C_{t}} & =u^{\prime}\left(C_{t}\right)-\lambda=0 \\
-\frac{\partial H}{\partial W_{t}} & =-\rho \lambda+\dot{\lambda}=-\lambda r_{t} . \\
\lim _{t \rightarrow \infty}\left[e^{-\rho t} \lambda(t) W(t)\right] & =0
\end{aligned}
$$

From the first order conditions (A.8) we get the standard formula for the evolution of consumption, $\frac{\dot{C}_{t}}{C_{t}}=\left(r_{t}-\rho\right) \theta$.

The optimization problem of a continuum of identical firms can be captured by a representative firm solving the problem:

$$
\max _{Y_{t} \geq 0}\left(Y_{t}-C\left(r_{t}, p_{t}, w_{t}, Y_{t}\right)\right)
$$

with $r_{t}, p_{t}$ and $w_{t}$ being the interest rate, the market price of the nonrenewable resource and the competitive wage respectively, and $Y_{t}$ being produced as in (3). In this setting, the firms do not optimize an intertemporal function; rather they face the same optimization problem at each instant. We follow Gaitan, Tol, and Yetkiner (2006) in their analysis and assume $C\left(r_{t}, p_{t}, w_{t}, Y_{t}\right)$ to be the optimized value of the cost minimization problem.

The profit maximization problem (A.10) can hence be rewritten as (abbreviating 1 $\alpha-\beta$ with $c)$ :

$$
\max _{Y_{t} \geq 0}\left(Y_{t}-\left(\frac{r_{t}}{\alpha}\right)^{\alpha}\left(\frac{p_{t}}{\beta}\right)^{\beta}\left(\frac{w_{t}}{c}\right)^{c} Y_{t}\right) .
$$

Profit maximization implies that marginal costs should equal one, which is the zero profit or perfect competition condition.

Referring to the household's utility maximization and knowing that the marginal costs equal unity in the case of perfect competition in the production sector, the capital stock evolves in the following way:

$$
\dot{K}_{t}=r_{t} K_{t}+p_{t} R_{t}+w_{t} L_{t}-C_{t}=Y_{t}-C_{t}
$$

Let us now consider the extractive sector: Supposing costless extraction, the representative firm solves the following maximization problem, taking $p_{t}$ as given:

$$
\int_{s=0}^{\infty} p_{s} R_{s} e^{-\int_{\tau=0}^{s} r(\tau) d \tau} d s \quad \text { satisfying } \quad(\mathrm{A} .13) \quad \int_{t=0}^{\infty} R_{t} d t \leq S_{0}
$$


The Hamiltonian for this problem reads as follows:

$$
H \equiv p_{t} R_{t}-\mu R_{t}
$$

The optimal extraction policy corresponding to the Hamiltonian (A.15) has to satisfy the following first order conditions:

$$
\begin{gathered}
\frac{\partial H}{\partial R_{t}}=p_{t}-\mu=0 \\
-\frac{\partial H}{\partial S_{t}}=-r_{t} \mu+\dot{\mu}=0
\end{gathered}
$$

together with the transversality condition:

$$
\lim _{t \rightarrow \infty} p_{t} R_{t} e^{-\int_{\tau=0}^{t} r(\tau) d \tau}=0 .
$$

Combining the first order conditions (A.16) yields the Hotelling rule:

$$
\frac{\dot{p}_{t}}{p_{t}}=r_{t}
$$

Rewriting the transversality condition (A.17) using (A.16) yields

$$
\lim _{t \rightarrow \infty} \mu e^{\int_{\tau=0}^{t} r(\tau) d \tau} R_{t} e^{-\int_{\tau=0}^{t} r(\tau) d \tau}=\lim _{t \rightarrow \infty} \mu R_{t}=0 .
$$

For an equilibrium to exist $p_{0}$ must be positive; otherwise the productive sector would demand an infinite amount of $R_{t}$, which would be unfeasible, as $R$ is bounded by $S_{0}$. Thus, $p_{0}=\mu$ must be positive and hence the resource constraint (A.14) must hold with equality. All this implies that for the transversality condition (A.19) to be satisfied, the following must hold:

$$
\lim _{t \rightarrow \infty} R_{t}=0
$$

Thus, here again, the economy decays in the long run.

\section{A.2.2 Lump Sum Taxation}

The most straightforward way of non-distortionary taxation is to levy a lump-sum tax on the private consumers. The households' maximization problem (A.4) stays the same; yet the budget constraint now changes to:

$$
C_{t}+\dot{W}_{t}=r_{t} W_{t}+\pi_{t}^{Y}+\pi_{t}^{R}+\pi_{t}^{L}-\tau_{t}
$$


with $\tau_{t}$ denoting the lump-sum tax. The Hamiltonian can be expressed as

$$
H \equiv u\left(C_{t}\right)+\lambda\left(r_{t} W_{t}+\pi_{t}^{Y}+\pi_{t}^{R}+\pi_{t}^{L}-\tau_{t}\right)
$$

The first order conditions with respect to consumption and capital do not change. The productive sector's optimization problem still equals (A.11) and is not affected by the lump sum tax. The capital and resource demand stays the same as in the case without taxation. Furthermore, also the extractive sector's optimization problem in (A.13) is not altered. Solely the investment path evolves in the following way:

$$
\dot{K}_{t}=r_{t} K_{t}+p_{t} R_{t}+w_{t}-C_{t}-\tau_{t}
$$

Though the intertemporal choices are not disturbed, the capital accumulation path differs from the case without taxes as the capital stock is 'eaten up' by the households in order to be able to pay the lump sum tax. This is reflected also in figure A.3, where the resource extraction in the lump-sum taxation case is close to the Social Planner case.

\section{A.2.3 Output Taxation}

A non-distortionary possibility to tax the non-productive sector is to levy a profit tax. The government thus receives a share $\tau_{t}$ of the output good $Y_{t}$.

With a profit tax the households' optimization problem stays the same as in the nontaxation case in (A.4). Equation (A.7) and the first order conditions in the non-taxation case also hold. The demand for both capital and resources, however, is changed as producers face the same maximization problem as in (A.11), yet with the output adjusted to $Y_{t}\left(1-\tau_{t}\right)$. The productive sector's demand for capital and resources is now diminished by $\tau_{t} Y_{t}$.

For a given output level $Y_{t}$ the (diminished) capital and resource demand is now

$$
K_{t}=\frac{\alpha}{r_{t}}\left(1-\tau_{t}\right) Y_{t}, \quad(\mathrm{~A} .24) \quad R_{t}=\frac{\beta}{p_{t}}\left(1-\tau_{t}\right) Y_{t} .
$$

The capital stock evolves in the following way:

$$
\dot{K}_{t}=r_{t} K_{t}+p_{t} R_{t}+w_{t}-C_{t}=\left(1-\tau_{t}\right) Y_{t}-C_{t} .
$$

The extractive firm faces the same maximization problem as in (A.13); the first order conditions (A.16) and the transversality condition (A.17) also hold. The Hotelling rule (A.18) remains unchanged.

The producers are indifferent between producing with or without taxes as their profits are always zero in a competitive environment. The resource producers face no change in 
their incentive to extract as this tax scheme leaves their revenues unaffected.

The resource extraction rates obtained in an economy with output taxation are smaller than in the political framework case, as indicated in our numerical solutions in figure A.3.

\section{A.2.4 Profit Tax}

Building on Dasgupta and Heal (1979), we consider a profit tax. ${ }^{24}$ The government now obtains a share $\tau_{t}$ of the resource owners profits $p_{t} R_{t}$ such that the effective price the resource owner faces equals $q_{t}=p_{t}\left(1-\tau_{t}\right)$.

The after-tax price per unit of resource that the resource owner obtains changes in the presence of a profit tax. Without taxation, the profit equals $R_{t} p_{t}$, whereas now, the profit occurring to the resource owners equals $R_{t} q_{t}=R_{t} p_{t}\left(1-\tau_{t}\right)$. The governmental revenues amount to $R_{t} p_{t} \tau_{t}$. In contrast to the sales tax, the revenues are a fraction of the total value of the resource sales, and not only of the amount sold. Again assuming costless extraction, the representative firm solves the same maximization problem as in (A.13), now, taking $q_{t}=p_{t}\left(1-\tau_{t}\right)$ as given.

The Hotelling rule holds with respect to the royalty price and can be rewritten as $\frac{\dot{p}_{t}\left(1-\tau_{t}\right)-p_{t} \dot{\tau}_{t}}{p_{t}\left(1-\tau_{t}\right)}=r_{t}$. In case the tax rate is constant, i.e. $\dot{\tau}_{t}=0$ the intertemporal allocation in the presence of taxes does not differ from the competitive allocation in the absence of taxation. ${ }^{25}$ The effect of a sales tax is then a reduction of the value of the resource deposit to the resource owner to a fraction $1-\tau$ of its original value, i.e. $q_{0}=(1-\tau) q_{0}^{*}$, with $q_{0}^{*}$ being the initial royalty price in the case without taxation (Dasgupta and Heal, 1979).

The profit maximization problem (A.11) of the productive sector and the utility maximization problem (A.4) are not affected by the tax. Yet, the household's income from the resource sector is altered and capital evolves according to:

$$
\dot{K}_{t}=Y_{t}-\tau_{t} p_{t} R_{t}-C_{t}
$$

A caveat of this solution is, however, that it might only be sustainable if the government does not announce the finiteness of the tax. Otherwise, the resource owners will decide to postpone the resource extraction until $T$, the known expiration date of the tax scheme.

An informal argument can be brought forward in favour of the claim that an equilibrium with perfect knowledge about the tax scheme cannot exist. At any instant close to the threshold $T$ a resource owner would have an incentive to postpone resource extraction as

\footnotetext{
${ }^{24}$ Royalties are another mode of payment to the government. They consist of a certain percentage of the value of the resource extracted (Dasgupta and Heal, 1979); thus they are in fact a tax on the gross revenue from resource sales. As we abstract from extraction costs, the effect of royalties amounts to the effect of a profit tax discussed in this section.

${ }^{25}$ In case of a rising (falling) tax rate, i.e. $\dot{\tau}_{t}>(<) 0$ the effect is equivalent to a rise (fall) in the interest rate, thus, a rising (falling) tax schedule encourages (discourages) initial consumption.
} 
he knows that the royalty price of the unextracted resource would increase after $T$. This reasoning holds for any instant arbitrarily close to $T$, up to the very initial point. Thus, resource depletion would be entirely delayed until after the economy passed the threshold $T$.

Furthermore, as mentioned above, this solution might only be feasible if the economic agents believe that the tax will stay in place forever. The importance of the issue of political discretion and commitment with regard to taxation has been taken up by the literature. Temporary taxes most likely provide resource owners with strong incentives to retime production in order to minimize the tax burden. Dasgupta, Heal, and Stiglitz (1981) note that if the significant increases in the rate of profit and sales taxation of resources like oil were anticipated, they would have lead to excessively fast exploitation of natural resources. Rao (2010) estimates how temporary taxes affect oil production decisions using well-level production data on California oil wells for the period $1977-2008$, and finds that the estimates suggest substantial retiming of oil production for operating wells. Issues of dynamic inconsistency of optimal (import) taxes also arise in a world with oil-importing and oil-exporting countries (Karp and Newbery, 1991).

\section{A.2.5 Interest Earnings Taxation}

A tax on the households' income from their asset holdings induces a distortion in the households' optimal choices. The interest earnings tax primarily affects the private households as the owners of the capital stock. The households' budget constraint now reads:

$$
C_{t}+\dot{W}_{t}=\left(1-\tau_{t}\right) r_{t} W_{t}+\pi_{t}^{Y}+\pi_{t}^{R}+\pi_{t}^{L}
$$

where $\tau_{t}$ denotes the tax rate on the interest earnings.

From the altered first order conditions we obtain that the formula for the evolution of consumption equals $\frac{\dot{C}_{t}}{C_{t}}=\left(r_{t}\left(1-\tau_{t}\right)-\rho\right) \theta$.

The firms in the productive sector still face the same problem (A.11) as in the case without taxation. The economy's capital stock, however, evolves according to

$$
\dot{K}_{t}=\left(1-\tau_{t}\right) r_{t} K_{t}+p_{t} R_{t}+w_{t}-C_{t}
$$

The resource owners' maximization problem changes to:

$$
\int_{s=0}^{\infty} p_{s} R_{s} e^{-\int_{k=0}^{\infty} r(k)\left(1-\tau_{k}\right) d k} d s \text { satisfying (A.14) }
$$


The corresponding Hotelling rule for the price path reads

$$
\frac{\dot{p_{t}}}{p_{t}}=r_{t}\left(1-\tau_{t}\right)
$$

Integrating this yields $p_{t}=p_{0} e^{\int_{t=0}^{\infty} r_{t}\left(1-\tau_{t}\right) d t}$, where $p_{0}$ ensures that the integral of sales over all periods equals $S_{0}$.

In order to expose the line of argumentation regarding the question whether the resource owners have an incentive to postpone extraction, let us assume for a moment that $r$ remains constant. Marking prices that sustain an intertemporal competitive equilibrium in the absence of taxation with a star, we have that $\frac{\dot{p}_{t}^{*}}{p_{t}^{*}}=r>r(1-\tau)=\frac{\dot{p}_{t}}{p_{t}}$, it has to hold that $p_{0}>p_{0}^{*}$ and thus the royalty price (which equals the market price for the resource here) is higher in the taxation case.

Though we do not solve for the equilibrium paths of the variables in this setup and thus cannot fully characterize the price and interest rate paths, it seems likely that the capital accumulation is reduced and thus the economy's output is lower than in the non-taxation case. These dampening effects on the capital and resource demands can partly be offset by the interest rate and the resource price falling. Consequently, it might be that the interest rate in the presence of taxes is lower as compared to the case without taxation and thus $p_{0}>p_{0}^{*}$. The higher resource price might discourage resource demand and mitigate the resource owners' incentive for higher extraction. Also, the lower real interest rate affects the resource price path via the Hotelling rule and might lead to lower extraction rates as compared to the non-taxation case. These considerations are confirmed by the numerical example in figure A.3. The resource extraction in this tax regime is lowest.

\section{A.2.6 Interest Earnings and Capital Gains Taxation}

Dasgupta and Heal (1979) also mention the possibility of a tax on capital gains, i.e. on the return from holding assets such as exhaustible resources. Ex ante this tax seems to be suitable to avoid incentives for postponement of the resource as the resource owner has to pay taxes on the resource still in situ. Denoting $\tau_{t}^{c}$ to be the rate of tax on capital gains while $\tau_{t}$ continues to denote the tax on interest earnings, the household now faces the following budget constraint:

$$
C_{t}+\dot{W}_{t}=\left(1-\tau_{t}\right) r_{t} W_{t}-\frac{\dot{r_{t}}}{r_{t}} \tau_{t}^{c} W_{t}+\pi_{t}^{Y}+\pi_{t}^{R}+\pi_{t}^{L}
$$

The Hamiltonian for the household's problem looks as follows:

$$
H \equiv u\left(C_{t}\right)+\lambda\left(\left(1-\tau_{t}\right) r_{t} W_{t}-\frac{\dot{r_{t}}}{r_{t}} \tau_{t}^{c} W_{t}+\pi_{t}^{Y}+\pi_{t}^{R}+\pi_{t}^{L}\right)
$$


Consumption now evolves according to $\frac{\dot{C}_{t}}{C_{t}}=\left(\left(1-\tau_{t}\right) r_{t}-\rho-\frac{r_{t}}{r_{t}} \tau^{c}\right) \theta$ and capital stock according to

$$
\dot{K}_{t}=Y_{t}-\tau_{t} r_{t} K_{t}-\frac{\dot{r_{t}}}{r_{t}} \tau_{t}^{c} K_{t}-C_{t}
$$

The resource owner now faces the following problem:

$$
\int_{s=0}^{\infty} e^{-\int_{k=0}^{s} r(k)\left(1-\tau_{k}\right) d k}\left(p_{s} R_{s}-\dot{p_{s}} \tau_{s}^{c} S_{s}\right) d s \quad \text { satisfying (A.14) }
$$

The Hamiltonian for this problem can be denoted as:

$$
H \equiv p_{t} R_{t}-\dot{p}_{t} \tau_{t}^{c} S_{t}-\mu R_{t}
$$

The Hotelling rule follows immediately from the first order conditions:

$$
\left(1-\tau_{t}^{c}\right) \frac{\dot{p_{t}}}{p_{t}}=r_{t}\left(1-\tau_{t}\right)
$$

Without any other taxation $p_{t}=q_{t}$. Thus, in case $\tau_{t}^{c}=\tau_{t}$ there is no distortion and the value $q_{0}$ of the deposit is not changed (Dasgupta and Heal, 1979). This gives no incentive to delay resource extraction until after the abrogation of the tax scheme. Still, extraction might be accelerated due to eventually higher $r_{t}$.

The combination of an interest earnings with a capital gains tax leaves the extraction path unaffected in our numerical example in figure A.3. Still, the extraction rates in case of taxation lie below those in a political economy setting.

\section{A.3 Numerical Examples}

\section{A.3.1 Numerical Method}

As we do not solve analytically for the optimal $\mu_{0}$ and $\lambda_{0}$ which correspond to a given initial capital and resouce stock, we approach the problem of finding a numerical solution to our model differently. For given initial values of $\mu_{0}$ and $\lambda_{0}$, and a given initial capital stock, we find an 'optimal' initial resource stock necessary to sustain the consumption, investment and resource extraction paths implied by $K_{0}, \mu_{0}$ and $\lambda_{0}$, using the first order conditions in (A.1). We argue that for an economy characterized by the given $K_{0}$ and the $S_{0}$ obtained by the numerical procedure, the chosen values for $\mu_{0}$ and $\lambda_{0}$ correspond to the optimally chosen initial multiplier values for this economy in case $S_{0}$ and $K_{0}$ was given. 


\section{A.3.2 Numerical Examples - Parametrization}

Table 8 displays the parameter values used in the numerical examples. Our parameters' values are comparable to those used by Benchekroun and Withagen (2011) in their numerical examples.

\begin{tabular}{lrrr}
\hline Model's Parameters & & Our Paper & $\begin{array}{r}\text { Benchenkroun and } \\
\text { Withagen (2011) }\end{array}$ \\
\hline Discount Rates & $\rho$ & 0.05 & 0.03 \\
& $\delta$ & 0.08 & \\
Production Function & $\alpha$ & 0.5 & 0.6 \\
& $\beta$ & 0.3 & 0.4 \\
Initial Capital Stock & & 5 & 1 \\
Elasticity of Intertemporal & $\theta$ & 1 & 1 \\
Substitution & $\psi$ & 1 &
\end{tabular}

Table 1: Parameter values for the numerical exercises. 


\section{A.3.3 Numerical Examples - Taxation}

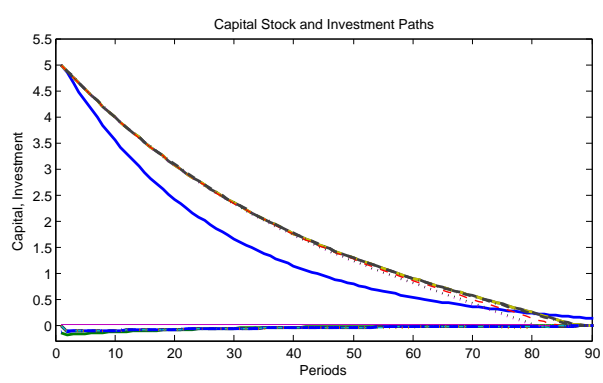

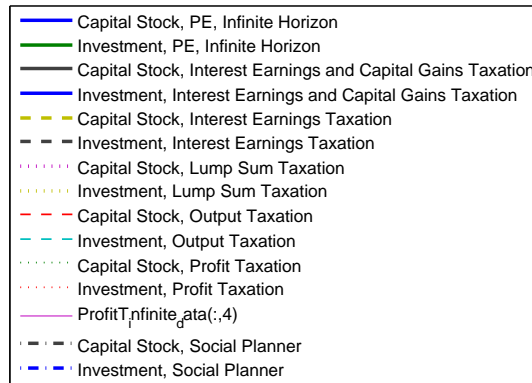

Figure A.1: Capital Stock and Investment Paths in the Taxation Regimes and the Political Economy

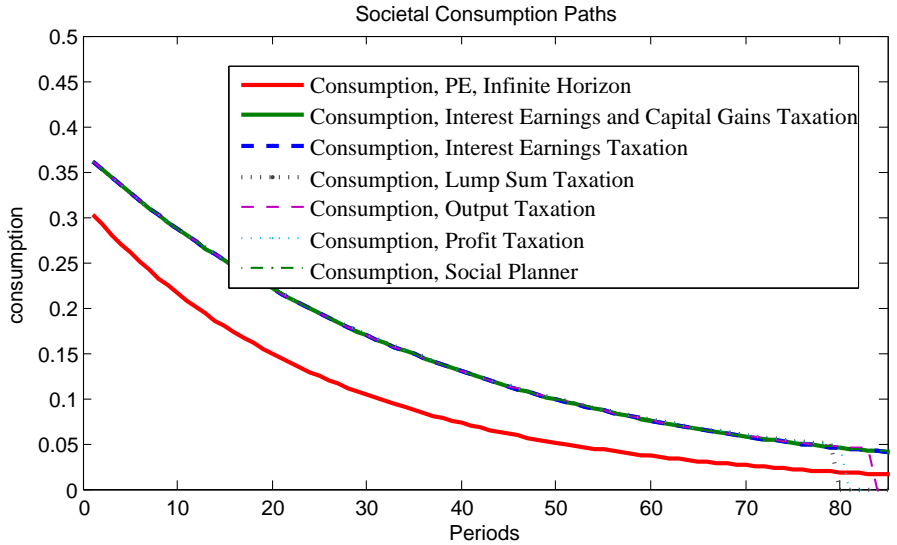

Figure A.2: Societal Consumption in the PE and in the Various Taxation Cases

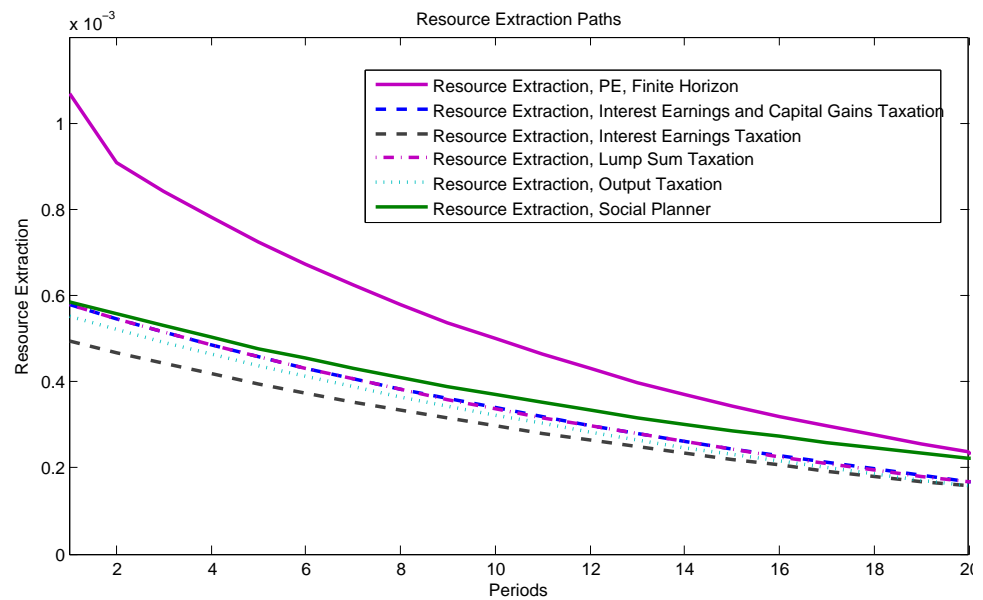

Figure A.3: Resource Extraction in case of Finite Taxation 


\section{B Endogenized Political Economy Framework}

The Lagrangian for the three period problem reads as follows:

$$
\begin{aligned}
\mathcal{L} & =\sum_{t=1}^{T}\left(\frac{1}{1+\rho}\right)^{t-1}\left\{\pi_{t-1}\left(u_{S}\left(C_{t-1}^{S}\right)\right) u_{P}\left(C_{t}^{P}\right)\right\} \\
& +\sum_{t=1}^{T}\left(\frac{1}{1+\rho}\right)^{t-1}\left\{\lambda_{t}\left[K_{t}^{\alpha} R_{t}^{\beta}-\left(K_{t+1}-K_{t}\right)-C_{t}^{S}\right]+\mu_{t}\left[S_{t}-S_{t+1}-R_{t}^{S}-R_{t}^{P}\right]\right\}
\end{aligned}
$$

with $\lambda_{t}$ and $\mu_{t}$ being the Lagrange multipliers. The following first order conditions need to hold, assuming an instantaneous utility function as in (6)

$$
\begin{gathered}
\frac{\partial \mathcal{L}}{\partial C_{t}^{P}}=\pi_{t-1}\left(u_{S}\left(C_{t-1}^{S}\right)\right) C_{t}^{P^{-1 / \psi}}-\mu(t)=0 \\
\frac{\partial \mathcal{L}}{\partial C_{t}^{S}}=\frac{\partial \pi}{\partial C_{t}^{S}} C_{t}^{S^{-1 / \theta}} \frac{C_{t+1}^{P}{ }^{1-1 / \psi}}{1-1 / \psi}-(1+\rho) \lambda(t)=0 \\
\frac{\partial \mathcal{L}}{\partial K_{t+1}}=-\lambda(t)+\left(\frac{1}{1+\rho}\right) \lambda(t+1) \alpha K_{t+1}^{\alpha-1} R^{S^{\beta}+1}+\left(\frac{1}{1+\rho}\right) \lambda(t+1)=0 \\
\frac{\partial \mathcal{L}}{\partial R_{t}^{S}}=\lambda(t) \beta K_{t}^{\alpha} R_{t}^{S^{\beta-1}}-\mu(t)=0 \\
\frac{\partial \mathcal{L}}{\partial S_{t+1}}=\frac{\mu(t+1)}{1+\rho}-\mu(t)=0 \\
\frac{\partial \mathcal{L}}{\partial \lambda_{t}} \lambda_{t}=\lambda_{t}\left(K_{t}^{\alpha} R_{t}^{\beta}-\left(K_{t+1}-K_{t}\right)-C_{t}^{S}\right)=0 \\
\frac{\partial \mathcal{L}}{\partial \lambda_{t}}=K_{t}^{\alpha} R_{t}^{\beta}-\left(K_{t+1}-K_{t}\right)-C_{t}^{S} \geq 0 \\
\lambda_{t} \geq 0 \\
\frac{\partial \mathcal{L}}{\partial \mu_{t}} \mu_{t}=\mu_{t}\left(S_{t}-S_{t+1}-R_{t}^{S}-R_{t}^{P}\right)=0 \\
\frac{\partial \mathcal{L}}{\partial \mu_{t}}=S_{t}-S_{t+1}-R_{t}^{S}-R_{t}^{P} \geq 0 \\
\mu_{t} \geq 0 .
\end{gathered}
$$

The multipliers thus evolve according to

$$
\frac{\lambda(t+1)-\lambda(t)}{\lambda(t)}=\frac{1+\rho}{1+r_{t+1}}-1
$$


and

$$
\frac{\mu(t+1)-\mu(t)}{\mu(t)}=\rho \text {, i.e. } \mu(t)=\mu_{0}(1+\rho)^{t}
$$

Proof of Proposition 2. The evolution of the politician's consumption is hence characterized by

$$
\frac{C^{P^{-1 / \psi}}(t+1)}{C^{P^{-1 / \psi}}(t)}=\frac{\mu(t+1) \pi_{t-1}}{\mu(t) \pi_{t}}=\frac{(1+\rho) \pi_{t-1}}{\pi_{t}}
$$

This follows directly from the first order conditions.

This is very intuitive: the discounted expected marginal utility in the next period has to equal the (expected - $\pi_{t-1}$ has already 'materialized') marginal utility in the present period.

The Hotelling rule is derived in the following way:

$$
\begin{aligned}
\frac{q_{t+1}-q_{t}}{q_{t}} & =\frac{\frac{\mu_{t+1}}{\lambda_{t+1}}-\frac{\mu_{t}}{\lambda_{t}}}{\frac{\mu_{t}}{\lambda_{t}}}=\frac{\frac{\mu_{t}(1+\rho)\left(1+r_{t+1}\right)}{\lambda_{t}(1+\rho)}-\frac{\mu_{t}}{\lambda_{t}}}{\frac{\mu_{t}}{\lambda_{t}}} \\
& =\frac{(1+\rho)\left(1+r_{t+1}\right)}{(1+\rho)}-1=r_{t+1}
\end{aligned}
$$

